\title{
LA INCLUSIÓN COMO PROYECTO DE CONOCIMIENTO EN RESISTENCIA $^{1}$
}

\author{
INCLUSION AS A KNOWLEDGE PROJECT IN RESISTANCE
}

\begin{abstract}
Aldo Ocampo González
aldo.ocampo.gonzalez@gmail.com ORCID: https://orcid.org/0000-0002-6654-8269

Centro de Estudios LatinoAmericanos de Educación InClusiva
\end{abstract} (CELEI), CHILE

1 Texto que presenta un extracto de la segunda sección de la conferencia magistral de inauguración impartida en el Congreso Interdisciplinario de Educación, celebrado en 2020 en la Universidad de Azuay, Ecuador. 
Para citar este artículo:

Ocampo González, A. (2021). La inclusión como proyecto de conocimiento en resistencia. ESPACIO I+D, INNOVACIÓN MÁS DESARROLLO, 10(26). https://doi. org/10.31644/IMASD.26.2021.a02

\section{RESUMEN}

Este artículo analiza las formas de producción del conocimiento de la educación inclusiva, las que son siempre formas de intervención-creaciónalteración, estrechamente ligadas a lo heurístico y a lo político. Ejecutan una operación abierta, inquieta y afirmativa de carácter no-dialectal, devenidas en un espacio contra-epistemológico que construye saberes que alteran la realidad, encarnan una fuerza heurístico-política que subvierte las convenciones establecidas en lo institucional y en lo alternativo. E1 objetivo central del presente trabajo es examinar las características centrales que definen los contornos de la educación inclusiva en tanto proyecto de conocimiento en resistencia. El trabajo recurre a una metodología de revisión documental crítica para su desarrollo, recurriendo a diversas bases de datos tales como SciELO, Wos, Scopus, etc. Al concebir la inclusión como un movimiento alterativo de las múltiples estructuras constitutivas de los sistemas-mundo, es posible reconocer su fuerza en tanto proyecto de conocimiento articula un conjunto de profundas transformaciones que alteran las estructuras intelectuales, éticas y políticas que regulan a la educación y la trama democrática y ciudadana. El entendimiento de la opresión, la dominación, las injusticias y la desigualdad es uno de sus puntos medulares, junto al ideal de transformación. Otra singularidad de su proyecto intelectual deja espacio para un amplio número de colectividades y comunidades de adherencia e interpretativas, vinculando una variedad de proyectos de conocimiento específicos. Su heurística proporciona nuevos ángulos de visión.

\section{Palabras Clave}

Epistemología de la educación inclusiva; nomadismo; exterioridad del trabajo teórico; imaginaciones desafiantes; transposiciones heurísticas. 
This article analyzes the forms of knowledge production, which are always forms of intervention-creation-alteration, closely linked to the heuristic and the political. They carry out an open, restless and affirmative operation of a non-dialectical nature, which has become a counter-epistemological space that builds knowledge that alters reality, embodies a heuristic-political force that subverts the conventional established in the institutional and alternative. The main objective of this work is to examine the central characteristics that define the contours of inclusive education as a knowledge project in resistance. The work uses a critical document review methodology for its development, using various databases such as Scielo, Wos, Scopus, etc. By conceiving inclusion as an alterative movement of the multiple constitutive structures of world-systems, it is possible to recognize its strength as a knowledge project that articulates a set of profound transformations that alter the intellectual, ethical and political structures that regulate education and education the democratic and citizen fabric. The understanding of oppression, domination, injustice and inequality is one of its core points, along with the ideal of transformation. Another singularity of his intellectual project leaves space for a wide number of collectivities and communities of adherence and interpretations, linking a variety of specific knowledge projects. Its heuristics provide new viewing angles.

\section{Keywords}

Inclusive epistemology of education; nomadism; exteriority of theoretical work; challenging imaginations; heuristic transpositions. 


\section{LA INCLUSIÓN COMO CONTRA-ESPACIO EPISTEMOLÓGICO}

$\mathrm{U}$ na de las características epistemológicas más relevantes de la educación inclusiva es su carácter micropolítico -no en su sentido tradicional, sino en términos de un espacio analítico contra-epistemológico y contra-enunciativo-, describe un proyecto de conocimiento en resistencia, un espacio contra-epistemológico que articula saberes que alteran la realidad, encarna una fuerza heurístico-política que subvierte las convenciones establecidas en lo institucional y en las coordenadas de lo alternativo -a mí juicio hoy, los movimientos significados como alternativos poseen cualidades muy similares a las de las propuestas hegemónicas, especialmente, las que proliferan en educación-. Por esta razón, puede concebirse la inclusión como un movimiento alterativo de las estructuras de regulación de los sistemas-mundo, un desafío abierto, un comentario performativo y un vector de disipación heurística.

Otra singularidad que entraña la construcción de un proyecto de conocimiento en resistencia deviene en la emergencia de un nuevo estilo de relación, subjetividad y afectividad. La inclusión -se funda en la tesis once de Feuerebach- es un singular signo de movilización de las fronteras heurísticas, penetra en nuevas lógicas de pensamiento devenido en la configuración de un poderoso umbral de transformaciones del que proliferan entendimientos complejos e imaginaciones desafiantes para pensar la construcción y/o comprensión del mundo contemporáneo.

La inclusión no es una práctica de asimilación, genera situaciones diferenciales de (micro)exclusión, (micro)opresión y (micro)dominación -frenos al auto-desarrollo y a la auto-determinación-, sino que es un poderoso mecanismo de reconfiguración de los sistemas-mundo, una heurística transposicional del conocimiento, una epistemología del agenciamiento, una forma de intervención político-ética diferencial y un dominio multirreferencial, multifuncional y multiexpresivo. Su forma epistemológica opera por fuera del código ontológico absoluto -figuración sustancialista-, estratégicamente deviene "en un como sí, cuya articulación no está en reproducir ni interpretar, sino en crear a partir de los elementos disponibles en una posición específica que, a su vez, nos constituye" (Ávila, 2014, p.170). La epistemología de la educación inclusiva es una forma constructiva estrechamente vinculada a lo político. Lo político de esta asume el deseo por la transformación, mientras que, lo propiamente epistemológico es, en cierta medida, la configuración de cambios creativos y arquitecturas alterativas del pensamiento - principio de positividad-. Es una empresa epistémico-política que se ubica más allá de lo crítico y lo post-crítico. Si bien, el aporte de lo post-crítico es aquello que regula gran parte de su matriz de constitución, lo cierto es que, rearticula dicho umbral de producción dando paso a algo completamente nuevo. La 
epistemología de la educación inclusiva surge de un conjunto de enredos genealógicos, muchos de ellos, procedentes del legado post. Su campo heurístico se enuncia y escucha en la exterioridad de dichas contribuciones.

La epistemología de la educación inclusiva no es una construcción eminentemente especulativa, se encuentra íntimamente imbricada con lo político de esta. Tiene como propósito no solo la recognición de su campo de saberes, sino más bien, la transposición, mutación y alteración de los fundamentos de la teoría educativa contemporánea -es un dispositivo de recognición de todos los campos y sub-campos de la Ciencia Educativa-. Analíticamente, la teoría de la educación inclusiva es sinónimo de teoría educativa, demuestra un efecto alter-epistémico. Proporciona nuevos ámbitos de visión y nuevos instrumentos conceptuales, asume la insistencia por la creación de conceptos que permitan leer el presente, fomentando un examen multidimensional-complejo acerca de las prácticas y problemas sociales y educativos que restringen la emergencia de una praxis ética y políticamente comprometida con un proyecto más amplio de cambio subjetivo y social.

Heurísticamente, la educación inclusiva es un complejo umbral de transformación del conocimiento. Una de sus razones de ser, radica, en cierta medida, en luchar contra las diversas formas de injusticias que atraviesan relacionalmente y de forma multinivel a amplios colectivos de la sociedad atendiendo, metodológicamente, cómo cada una de estas singulares formas de freno al desarrollo humano generan singulares repercusiones regenerativas y performativas en la trama escolar. Concebir la educación inclusiva como proyecto intelectual en resistencia sugiere reconocer que estamos en presencia de un dispositivo de conocimiento de base amplia que configura un ensamblaje dinámico e inacabado, de ninguna manera disfruta de una definición estable y definitiva, sino intensamente inestable, abierta, inquieta e impredecible. Su núcleo analítico es configurado por un conjunto de preocupaciones e intereses interdependientes, devenidas en la formación de un terreno atravesado de forma multiaxial por diversos proyectos de conocimiento e informados por movimientos sociales críticos, cuyas discusiones y preocupaciones residen en lo más profundo del campo. Cuando la inclusión es empleada como forma de justicia social y educativa, nos enfrentamos a la cristalización de su praxis crítica.

La inclusión constituye una nueva categoría de análisis aplicada a un conjunto de diversas prácticas, estrategias de análisis, decisiones y formas de intervención políticas, modos de exploración metodológicas, formaciones conceptuales, etc. Estudiamos un cuerpo de conocimiento en permanente movimiento - principal condición de producción del campo-, operación que sigue la lógica expuesta por Zemelman (1989), “dada-dándose-por-dar”. Sin embargo, sus contornos generales nunca han sido bien delimitados. Uno de 
sus aspectos definicionales consiste en afirmar que es una teoría sin disciplina, una operación post-disciplinaria y un dispositivo heurístico de rearticulación de lo post-crítico. Mientras que uno de sus problemas definicionales de mayor alcance se reduce a la baja intensidad de su índice de singularidad, esto es, académicos, investigadores, trabajadores culturales y de la política pública y profesionales de la educación, creen saber qué es la inclusión, al tiempo que son incapaces de explicarla en profundidad, o bien, muchos creen conocerla, pero encuentran obstáculos para definirla. Sumado a ello, la conceptualización que efectúan refleja un significante drásticamente diferente al que demanda su autenticidad, reconociendo que diversos grupos poseen explicaciones diferentes para aproximarse al fenómeno. Hablamos entonces de inclusión como metáfora.

Otro problema definicional del campo reside en la ausencia de reglas analítico-metodológicas claras producto del encubrimiento de su sustancia y modos de existencia. La atención a sus modos de legitimación es crucial, puesto que fomenta interconexiones en zigzag entre lo que realmente cuenta como parte de su centro epistémico auténtico y los mecanismos de transformación de sus formas definicionales y condicionales del campo y del propio concepto -sintagma heurístico-. La educación inclusiva enfrenta complejos dilemas de definición. El interés por las definiciones no han de entenderse como prácticas iterativas cuyo objetivo es que fijen su política de intelectualidad. En el caso de la inclusión, es algo que se encuentra en permanente movimiento, inaugura un campo inquieto e inacabado, es un punto de partida en el análisis, nunca de clausura, inaugura nuevos puntos de focalización analítica.

La interrogante por las condiciones que definen la naturaleza y los modos de existencia de la inclusión como proyecto de conocimiento en resistencia, es clave para situarnos en la naturaleza de su dominio epistemológico. Se convierte así en un intensificador del pensamiento, en una singular praxis política y en un dispositivo de giro de la vida social y escolar. En tanto umbral de transformación del mundo posee la capacidad de crear dispositivos de subjetividad singularizante -eje clave en la política ontológica de la inclusión-. Afirmación que nos conduce al reconocimiento de que su política ontológica reafirma un carácter de lo menor, rompe con las implicancias sustancialistas del campo, legitima el halo de heterogeneidad que reside en cada singularidad que, a su vez, son múltiple.

Al significar la educación inclusiva como un proyecto de conocimiento en resistencia, se convierte en un contra-espacio epistemológico, devenido en la configuración de un plan para imaginar la educación y el devenir social de un modo completamente alterativo y diferente a lo conocido. La inclusión es siempre sinónimo de una heurística disruptiva y de entendimientos complejos, es también un compromiso político deliberado y un conjunto 
de pasiones éticas y estéticas, una cartografía del presente. ¿Qué sugiere este singular modo de cartografización? La inclusión es el efecto de un sistema de transformación total.

¿La inclusión está fuera de la educación, es educación, o bien, opera sobre ella? Si bien, es esencialmente educativa, no se limita a esta regionalización, ya que no se reduce exclusivamente al trabajo del educador -es sustantivo a su labor, permite recuperar el sentido intrínseco de esta-, la inclusión se encuentra en todas partes. Incluso se despliega en campos que no tiene relación directa con la educación por relacionamiento extradisciplinar. Es algo que no se limita a lo que uno puede encontrar en los libros o en las estructuras institucionales de formación. Desempeña un papel crucial en la organización del mundo y en la construcción de otros mundos, de la cultura y de la vida política, es un espacio de complejas tensiones y tránsitos de carácter nomadista y diaspórico. Es un mecanismo de lectura del presente, un esfuerzo por pensar una nueva subjetividad capaz de convivir con las continuas transformaciones. Es una estrategia para desafiar a la educación global e imaginar de un modo diferente el pensamiento educativo y su praxis, comprometida con un proyecto más amplio de cambio subjetivo y social.

Si bien, gran parte de los programas de cambio han agotado su función histórica, el deseo por la justicia social y la transformación progresiva es una de las principales manifestaciones de su conciencia ética. Es un territorio que opera por transposición de diferentes objetos, métodos, conceptos, teorías, proyectos políticos, compromisos éticos, discursos, disciplinas, interdisciplinas, territorios, proyectos de conocimientos, etc. Asume una forma novedosa para imaginar de un modo diferente sus formas de producción del conocimiento. Es una fuerza epistemológica subversiva, un itinerario que favorece la heterogénesis, el nomadismo, la complejidad y la multiplicidad.

\section{UN SABER NÓMADE, UN CAMPO SINTAGMÁTICO}

¿Nomadismo epistemológico? Las formas de producción del conocimiento constituyen complejos mecanismos de intervención-creación-alteración, no se reducen a meras cuestiones especulativas y a herencias convergentes en este singular contexto heurístico. Forja una manera novedosa de concebir la producción de conocimiento, su objeto no procede por vía normativa, es un dispositivo que desborda e interroga los saberes y las formas interpretativas legitimadas, su trama epistemológica opera por fuera del código ontológico absoluto, estratégicamente deviene en un como-sí, cuya articulación "no está en reproducir ni interpretar, sino en crear a partir de los elementos disponibles en una posición específica que, a su vez, nos constituye. Ni sujeto/objeto ni significante/significado" (Ávila, 2014, p.170). 
Articula un conjunto de profundas transformaciones que alteran las estructuras intelectuales, éticas y políticas que regulan a la educación, la trama democrática y las arquitecturas ciudadanas. Heurísticamente, es un campo de profundos intereses teóricos, políticos y éticos. Rescata la noción de singularidades múltiples -categoría que impacta en lo teórico y en lo político; redefine el espacio cultural, social y educativo-. Hasta aquí, los sujetos de la inclusión mainstream y liberal son los otros de la modernidad; reproducen la presencia de un conjunto de binarismos clásicos -sustentados en la gramática del esencialismo-individualismo-. Mientras que, al ser concebida como un espacio contra-discursivo y de contra-subjetividades, lleva al sujeto -indistintamente de sus formas categoriales- a una etapa superior de realización, coherente con las formas del post-humanismo propuestas por Braidotti (2009). Su dominio epistemológico se arma y desarma permanentemente.

De este modo, se propone "moderar la voz teórica dentro de nosotros y de intentar ocuparnos de nuestra situación histórica de un modo diferente" (Braidotti, 2004, p. 113). Este énfasis de creatividad "hace que se produzca un viraje del lenguaje teorético a la producción de cartografías y figuraciones o ficciones políticas" (Ávila, 2014, p.174). La inclusión, al encontrarse presente en todos lados, ha de arraigarse a eventos de la vida real y, por extensión, asumir el deseo crítico de justicia social y transformación progresiva, reinventando las manifestaciones de nuestra conciencia ética.

Al afirmar que la educación inclusiva posee una compleja naturaleza alterativa, refiero a un conjunto de representaciones afirmativas de tipo creativas y dislocativas, una forma no-reproductora de lo mismo (Braidotti, 2004), opuestas a las figuraciones de las alternativas que trabajan bajo la lógica de reiteración de una determinada posición. Lo alterativo no logra ser capturado por la hegemonía y la reproducción. Es, en esto, donde se inscribe parte de la naturaleza epistemológica de la educación inclusiva, concebida como un sistema de relocalización heurístico-política de carácter estratégica, un desplazamiento que da paso a la creación, operación que implica la transformación y la emergencia de nuevos espacios, la inclusión nunca es un mero sistema de imaginación proyectiva. Su dominio puede ser lecturado en términos de un espacio multi-estratificado inscrito en un afuera dinámico.

La educación inclusiva como área o regionalización de estudio proporciona un conjunto de prototípicos radicales, es una forma epistemológica que actúa por complejos mecanismos de rearticulación de campos atravesados por lo post -este prefijo, en la interioridad del dominio no sigue una lógica lineal-, específicamente, devela una operación próxima al vuelco de cada una de las teorías post-críticas que en ella confluyen. Si bien, lo post-crítico constituye parte de su estructura genealógica, su naturaleza y autenticidad 
se cristaliza más allá de esta. Su objeto, campo y método opera en la rearticulación de cada una de tales contribuciones.

Es muy común tender a pensar que la educación inclusiva es un signo post-crítico. Si bien hasta cierto punto lo es, ciertamente su objeto teórico, empírico y de análisis se informa a partir de cada una de estas teorías -en adelante, legados y memorias epistemológicas-, su campo de constructividad y regulación cognitiva se construye más allá de estas. Nuevamente retorna la insistencia constructiva de la exterioridad del trabajo teórico. La construcción epistemológica que planteo sobre educación inclusiva recurre a un amplio corpus de conocimientos situados, en su mayoría, legados por las epistemologías sub-alternas -comparte con ellas un conjunto de premisas meta-metodológicas-; trasciende sus planteamientos, los redobla creando algo completamente nuevo. La educación inclusiva no es una teoría post-crítica, es algo que se encuentra más allá de sus presupuestos. Al confundir lo especial con lo inclusivo nos estamos enfrentando a una singular forma de monocultivo mental cuya morfología heurística es regulada por un conjunto de relaciones interiores, que es lo que atrapa el fenómeno en una mímesis y en una extensión de lo especial. La educación especial es una forma de lo inclusivo, lo inclusivo no es necesariamente una forma de lo especial, es un fenómeno de mayor alcance. Rompe con las relaciones internas que la anclan a los modelos epistemológicos normativos. Detengámonos unos instantes a analizar esta singular imbricación.

La educación inclusiva, en tanto regionalización epistémica toma distancia de métodos y disciplinas académicas tradicionales, actúa por diaspórismo, nomadismo y (des)vinculación, la producción de su conocimiento se imbrica en la lucha por captar el presente -filosofía del exterior-. Construye una nueva modalidad de codificación, una nueva composición afirmativa de subjetividades, cuya capacidad relacional no se encuentra confinada dentro de las dictaduras y/o dependencias epistémicas y ontológicas clásicas. Producto del éxodo que fomenta su emergencia, sus fuerzas constructivas se encuentran permanentemente en des-territorialización y re-territorialización, cuyo proceder heurístico acontece a través de singulares modos afirmativos, no así por vía de reactividad en la producción del conocimiento -fórmula mainstream-. Es un campo de irremediables y permanentes aperturas, un dispositivo de naturaleza multicapa dinámica, un saber que actúa en sujetos encarnados, en sus relacionales y afectividades, construye una trama ética coherente con los planteamientos de Braidotti (2009), respecto de la ética diferencial que traza un doble vínculo entre las fuerzas de transformación y la construcción de una nueva praxis ética. 


\section{INCLUSIÓN: UNA ZONA INTENSAMENTE SENSIBLE}

¿Qué es lo que oyes cuando oyes la palabra inclusión? Si atendemos estrictamente a la diferenciación ofrecida por Bal (2009), es posible afirmar que la inclusión es al día de hoy una palabra, no un concepto como tal. En tanto palabra, nos llena de esperanza, de fuerza y vigor, de intensa relatividad, impone una figuración que se abre a aquello que nos permite seguir luchando, toma distancia de cualquier significante a favor de la ingenuidad. Hasta aquí, su función inscribe una singular forma de vivir la vida, una modalidad de comportamiento, de comprender el mundo que nos rodea, una forma de utilizar nuestra mente y consciencia. Al afirmar que la inclusión cumple las mismas funciones de una filosofema sostengo que es algo que encontramos en todas partes, hacemos carne este adjetivo, sustantivo y verbo cuando nos relacionamos con los otros, no se es inclusivo sólo en la escuela -esta es una condición inherente al quehacer educativo-, se es inclusivo al interactuar, al caminar, al relacionarnos, etc. Esta crea un aprendizaje permanente.

Si bien el término inclusión y el sintagma educación inclusiva son empleados de diversas maneras por diferentes grupos, lo cierto es que esta puede ser descrita en términos de metáfora, es decir, explicaciones elaboradas por diferentes grupos y empleadas con fines particulares. Es un discurso que no es propiedad de nadie. Hasta aquí la educación inclusiva puede ser descrita en términos de movimiento, especialmente al ser empleado como una consigna y, en ocasiones, para identificarse en torno a un extraño ideal de diversidad que colinda con la empresa ontológica que concibe a esta categoría en términos de asimilación. ¿En qué tipo de manifestaciones se emplea el ideal de inclusión? Si bien no hay protestas específicas sobre grupos y espacios que clamen la inclusión como tal, o más bien, con esta denominación. Ciertamente es un objeto de lucha permanente en diversos proyectos de conocimiento y movimientos sociales contemporáneos críticos, cuyas articulaciones, conceptos y desarrollos habitan lo más profundo de su dominio. Si bien la gente quiere saber de inclusión cada vez más, las lecciones y los usos que colindan en diversas latitudes del mundo siguen trabajando en un tropismo negativo, es decir, emplean un repertorio de conceptos que distorsionan el objeto auténtico de esta. Es un campo que despierta el interés de las personas. La educación inclusiva es un campo conformado por múltiples intereses y por complejas influencias. Una de sus tantas singularidades reside en su capacidad para enunciarse con diferentes palabras, objetos de lucha y propósitos de trabajo.

La inclusión es un concepto que nos interpela, nos habla sobre nosotros, sobre nuestra existencia y, singularmente, sobre nuestra vida. Para que esta tenga efecto en nuestras vidas -tramas biografías- debemos desalojarnos de ellas, sugiere hacerse parte de algo, próximo a un compromiso político 
global y situado. Este es un dominio que supuestamente viaja y acontece en términos de una gran estructura que nos hace parte de algo, pero esta ficción de regulación, a tal punto, nos cuenta su historia a su manera. Para convertirse en un arma de transformación del mundo, necesita asumir otros problemas, contar otras historias, legitimar otras voces, etc. ¿Cómo nos enseña a hablar la inclusión a favor de ella y en contra de la violencia y la injusticia? Esta interrogante nos invita a reflexionar acerca de los dispositivos semiológicos con los que interactuamos, así como los espacios y las personas que nos transmiten este mensaje. En términos de movimiento, lo que este enfoque no tiene claro, es justamente, la conciencia de lo inclusivo. Ella, es el movimiento que busca acabar con la exclusión, la discriminación silenciada, la violencia estructural, el sexismo, la indiferencia colectiva, el racismo y, ante todo, pone en tensión los discursos significados en términos críticamente democráticos, los que encubren una amplia variedad de formas de desigualdad. Ante todo, es un compromiso de visibilización de toda forma de (micro)opresión y (micro)dominación.

No porque hablemos de inclusión, o bien, las políticas y programas de formación giren en torno a sus propósitos -propios del mainstream-, quiere decir que esto ocurra. No todo el mundo reconoce eso a lo que uno desea poner fin o en su defecto, inaugurar. Este enfoque enfrenta el desafío de aprender a reconocer y actuar en la estructura y en las piezas fundamentales de las injusticias propias del capitalismo actual. La educación inclusiva refuerza sus planteamientos al seguir insistiendo sobre estos fenómenos. Hasta aquí, a mi juicio, la inclusión de la que más hablamos configura una insuficiente comprensión del mundo, no logra explicar cómo se producen o continúan reproduciéndose en diversos planos de la vida social, una amplia variedad de patologías sociales crónicas, constitutiva de los sistemas-mundo que experimentamos. Es, justamente, esta repetición lo que constituye su fuente de dificultad, uno de los múltiples límites del pensamiento.

La inclusión se aprende en la micropraxis, es descrita, mediante la metáfora del 'trabajo para la casa' -tomo esta expresión de la obra de Ahmed (2005), pues ejemplifica brillantemente las configuraciones de la micro praxis a la que aludo en diversas secciones de este trabajo-, es una tarea que uno se asigna a sí mismo, una toma de conciencia, una deformación de nuestra auto-conciencia. Nos invita, tal como señala Ahmed (2005), a aprender acerca de nuestro malestar en el mundo, sobre nuestras intenciones de cambio, producción del deseo y experiencias de vida. El trabajo para la casa, es una analogía en torno a la idea de intimidad crítica o intimidad reflexiva, en proyección con el archivo de imágenes de nuestra biografía, sugiere volcarse a zonas más profundas de nuestra vida, de nuestras interacciones, de nuestros relacionamientos, etc., deviene en un singular proceso de intimidad, lo que implica la reconstrucción de nuestra trama biográfica, 
de nuestros afectos, pasiones y sentimientos. Todos ellos, ejes claves en la construcción de la teoría de la educación inclusiva. Teóricamente los entendimientos de la educación inclusiva la describen como un gran movimiento de transformación social y político. Al transitar por la experiencia de la exclusión nos ayuda a descubrir una infinidad de formas de mundos posibles. Aprender sobre inclusión es aprender sobre el mundo.

\section{TENSIONES ONTOLÓGICAS: EL SALTO DESDE EL SUSTANCIALISMO AL MATERIALISMO}

La educación inclusiva configura un programa intelectual articulado en la exterioridad del trabajo teórico, amalgama diversas trayectorias de conocimiento -enredos genealógicos de dispersión-. Construye una política ontológica de lo menor que toma distancia del diferencialismo que emerge por vía del pensamiento idéntico - pieza angular que, en parte, fundamenta y legitima un corpus de esencialismos-individualismos en la organicidad del campo-. Una ontología de lo menor es coherente con el principio de diferencialidad, ratifica que cada singularidad es heterogenea en sí misma, es una expresión de variación múltiple e infinita. Coincido con De Landa (2016), al observar que las formas ontológicas dominantes, eurocentradas, coloniales y occidentales-hegemónicas, son las mismas que han regulado el discurso mainstream y liberal de la inclusión. En ella, la identidad se convierte en un factor restrictivo de la propia diferencia, incluso las políticas de identidad y alteridad reproducen este fallo de aproximación analítico.

El campo epistemológico de la educación inclusiva construye una figuración ontológica infinitamente mayor, propiedad del carácter abierto del mismo, es esto, lo que permite llegar a la construcción de cosas más amplias, inacabadas e inaugurar nuevas perspectivas de análisis. La ontología de la inclusión es algo abierto -lo abierto nos permite llegar hacia estados más elevados del pensamiento. Lo abierto se encuentra en perpetuo devenir, nada está fijo en él. Estas propiedades son claves en la comprensión de la estructura de conocimiento de la educación inclusiva, sus elementos de configuración alcanzan su funcionamiento mediante complejas fuerzas de desterritorialización y reterritorialización, develando un campo que se configura en diversos planos. La estructura y el campo de conocimiento de la educación inclusiva es configurada mediante un corpus de "híbridos de fuerzas plegando y diseminando singularidades a través de una multicombinatoria en constante actualización" (Castillo, 2019, p.236)-, en permanente devenir. En este punto coincido con Braidotti (2006), puesto que, instaura una ontología materialista que trabaja para destruir las huellas de enunciación de un ser humano dominante. Detengámonos unos instantes en este punto. Braidotti (2009), consolida su trabajo académico a través de una 
noción positiva de la diferencia. Tal afirmación es sostenida mediante una red de individualismos-esencialismos que fundan el problema ontológico de los grupos sociales -operación también concebida como ontología sustancialista- que coloca en desmedro y cosifica a un amplio grupo de personas, justificando así un corpus de políticas públicas que no hacen otra cosa que reproducir un efecto de asimilación y un problema multicategórico para justificar su tarea en torno a los significantes pasivos de la inclusión,

[...] donde una idea muy específica del ser humano se ha impuesto sobre otras, funcionando como un ideal o canon regulativo con el que contrastarse y al que aspirar. En tal marco, la diferencia pierde gran parte de la riqueza de su significación, al ser entregada a una estructura de pensamiento en la que prima la unidad o la homogeneización de las subjetividades, ya que aquellas que no responden o que se distinguen de la hegemónica, bien son segregadas o situadas en los márgenes, cuando no son reprimidas y perseguidas, bien se les adjudica una posición de subordinación respecto de aquella, conformando un sistema social marcadamente jerárquico y estratificado (González, 2018, p.174).

El principio de identidad se organiza en torno a un criterio de unidad, en ella la materia de lo humano es una sola, produce una mismidad y unidad que fomentan diversas formas clasificatorias de lo mismo. El sujeto de la inclusión -mainstream, falsificada o mímesis de lo especial, liberal y capitalista- es clasificado en torno a un principio de naturaleza individual. El principio de identidad actúa en términos de un principio de restricción, el poder de la diferencialidad y de la variabilidad humana, es esto lo que permite afirmar que el sujeto de la inclusión es propiedad de lo múltiple y de lo menor, un sujeto con una gran riqueza ontológica. Las extrañas articulaciones que definen la política de educación inclusiva -refiero específicamente, en términos de ensamblajes intelectuales- asumen imperceptiblemente lo que Lacan (1970), denomina impasse de la diferencia o en Young (2002), el problema ontológico de los grupos sociales. En efecto,

[...] la diferencia deviene en torno a lo diferente, propiciando que salgan a flote las diferencias que ocultan la mismidad en su afán de moldear las entidades a partir del principio de ocultación que promueve la identidad. Por este motivo, la diferencia emerge como un gran cúmulo de intensidades que no se captan ni por lo general, ni tampoco por lo particular, pues las relaciones diferenciales de cada vibrar energético afloran en grados de intensidad diversos, y escalas temporales-espaciales distintas (Castillo, 2019, p.235).

El estudio de las condiciones de producción epistemológicas de la educación inclusiva, no sólo se centra en la comprensión de los mecanismos que crean 
y garantizan la emergencia de su conocimiento, sino que, además, focaliza en las fuerzas de apropiación de sus elementos, imprimiendo un sentido determinado sobre cada una de ellas. Coincidiendo con Castillo (2019), tales fuerzas son concebidas en términos de voluntades, es esto lo que permite al campo estar en constante aleación con elementos intensamente diferentes -principio epistemológico de heterogénesis-, evitando así caer en la repetición. Es un dominio compuesto por intensidades variables, por múltiples ensamblajes que mutan hacia otros pliegues, cuya estructura sigue la lógica de:

[...] enjambres de diversos materiales, esparcidos y plegados por los múltiples espacios de posibilidades energéticas, mutando todo el tiempo hacia diversos pliegues. De tal modo, el que todos los dinamismos interconectados estén en una proliferación infinita en un juego de ajustes y desajustes en el que los múltiples flujos viven una metamorfosis constante de unos a otros, sin detenerse un solo instante (Castillo, 2019, p.237).

La educación inclusiva no posee estatus de figuración heurística preformada, lo mismo sucede con la educación. En ella, cada uno de sus elementos se encuentra en permanente mutación, afectados a ritmos dispares, dando cuenta de una constelación que puede ser significada en términos de "hiatos cósmicos, propiciando así todo tipo de interpenetraciones y contagios" (Castillo, 2019, p.237). La educación inclusiva en tanto estructura, objeto, campo y saber, se encuentra cargada de dinamismos constantes, regulados por principios de variabilidad, movilidad y continuidad, a través de ellos, se devela un campo de gran fuerza de infinitud analítico-metodológico. Es un terreno habitado por múltiples recursos y singularidades constructivas de diferente naturaleza que puede ser significado en términos de "contenedor de multiplicidades en constante configuración” (Castillo, 2019, p.238).

La inclusión nos conduce a una onto-logica-materialista, inaugura un debate en torno a la presencia y recognición de singularidades de naturaleza heterogéneas -axioma fundante de su política ontológica y principal clave heurística de construcción de su saber-, cuyo principio de articulación se estructura en torno a la lógica de integración/desintegración gracias a sus diferenciaciones. Si partimos de la afirmación: la inclusión es el efecto de una transformación total. ¿Qué desencadena tal fenómeno? Si bien los sistemas de razonamientos empleados en la operación por falsificación -efecto de simulacro, travestización y mímesis con lo especial-, imponen un significante que no se condice con la naturaleza del campo, dando paso a un conjunto de ideas erróneas para fundamentar su tarea heurística producto del ausentismo de fundamentos oportunos.

La naturaleza performativa y alterativa de la inclusión refleja un singular modo de irrupción en el mundo, asemejable a un desencadenamiento 
político-imaginativo que actúa por sí sólo. Su potencia analítica performa la realidad a través de un movimiento "dado-dándose-por-dar", es algo que se produce en la praxis -entiéndase esta última categoría, desde el punto de vista de la filosofía de la praxis planteada por el marxismo-. El desmembramiento del significante de la inclusión de lo especial -palimpsesto epistémico de la inclusión que impone un nuevo rostro de lo especial. Sin embargo, conduce a una sustancialización repetitiva de atrapamiento, una falsa edipización - amerita una lectura acabada en la interioridad del proceso de falsificación y de la tradición teórica que fundamenta su legado en ella. Si bien lo especial puede ser una forma de inclusión, la inclusión no es necesariamente una forma de lo especial. Es un dispositivo de imaginación desafiante frente a los tiempos que nos toca vivir. La inclusión es una necesidad patente y legible en todos los campos del desarrollo humano, no es exclusiva de lo educativo -esto es, lo que hace que su objeto sea ambivalente y multiescalar, es decir, funcione de diversas formas-.

¿En qué tipo de manifestaciones se emplea el ideal de inclusión? Si bien no hay protestas específicas sobre grupos y espacios que clamen la inclusión como tal o más bien, con esta denominación; ciertamente es un objeto de lucha permanente en diversos proyectos de conocimiento y movimientos sociales contemporáneos críticos, cuyas articulaciones, conceptos y desarrollos habitan lo más profundo de su dominio. Si bien, la gente quiere saber cada vez más de inclusión, las lecciones y los usos que colindan en diversas latitudes del mundo siguen trabajando en un tropismo negativo, es decir, emplean un repertorio de conceptos que distorsionan el objeto auténtico de esta. Es un campo que despierta el interés de las personas. Habrá, entonces, que distinguir sus diversos ejes de análisis en torno a las formas constitutivas de sus intereses y contornos teóricos, metodológicos y políticos. La educación inclusiva es un campo conformado por múltiples intereses y por complejas influencias. Una de las tantas singularidades de esta reside en su capacidad para enunciarse con diferentes palabras, objetos de lucha y propósitos de trabajo. La inclusión está en todas partes, es un acontecimiento micropráctico. ¿Por qué necesita estar en todas partes?, ¿dónde la encontramos?, ¿dónde este nos encuentra?

La inclusión es un concepto que nos interpela, nos habla sobre nosotros, sobre nuestra existencia y, singularmente, sobre nuestra vida. Para que la inclusión tenga efecto en nuestras vidas -tramas biografías- debemos desalojarnos de ellas, sugiere hacerse parte de algo, próximo a un compromiso político global y situado. La inclusión supuestamente viaja y acontece en términos de una gran estructura que nos hace parte de algo, pero esta ficción de regulación, a tal punto, nos cuenta su historia a su manera. La inclusión para convertirse en un arma de transformación del mundo necesita asumir otros problemas, contar otras historias, legitimar otras voces, etc. 
La educación inclusiva, como teoría, reafirma el concepto de Deleuze y Guattari (1968) de ensamblaje. ¿Cuál es el beneficio heurístico de esta noción? La inclusión como ensamblaje nos aproxima al contexto de constelación. Las constelaciones sugieren la creación de algo sin copiar lo anterior. Es una tarea filosófica de orden materialista y dialéctica, afirma Buck-Morrs (1997). Las constelaciones son un gran grupo de ideas que ensamblan un determinado fenómeno o figuración de este, que son intensamente inestables. Son fragmentos de ideas, conceptos, métodos, teorías, sujetos, territorios, etc. que al yuxtaponerse van configurando una determinada constelación que analiza e ilumina la realidad y sus diversos sistemas-mundos. La gran mayoría de estas singularidades constructivas permanecen en estado de aislamiento, cuyas imbricaciones y conexiones no son siempre bien comprendidas en la intimidad de los sistemas de aleaciones que configuran el dominio de la educación inclusiva. Su organicidad se obtiene "transformando conceptos tradicionales, invirtiendo dialécticamente sus relaciones y desafiando las consignas de la 'segunda naturaleza'" (BuckMorrs, 1997, p.199).

El campo epistemológico de la educación inclusiva puede ser concebido bajo el concepto de constelaciones, puesto que construye, ensambla y modeliza una singular figuración analítico-metodológica a partir de elementos aislados, no siempre bien comprendidos o alejados en su función al objeto de esta, cuyas imbricaciones y aleaciones develan vínculos creativos e intensamente inestables. Lo que las constelaciones hacen es refuncionalizar heurísticamente un determinado dominio, asimismo son fenómenos que poseen la fuerza de desenredar diversos problemas y efectos.

La educación inclusiva es una constelación específica a partir de los elementos constitutivos de su fenómeno, fomentando que sus ejes de constitución se tornen visibles en su interioridad. Su dominio entendido en términos de constelación no funciona exclusivamente bajo el significante de la simple reagrupación de recursos constructivos. Si bien todos ellos operan bajo el principio de heterogénesis, sus modalidades acontecen bajo la performatividad de lo rearticulatorio. Las constelaciones operan en términos de alteraciones en las formas de construcción de sentido, cada una de ellas se erige al interior de la historia intelectual de esta, así como en sus trayectorias y enredos genealógicos.

\section{5. ¿ENSAMBLAJES HEURÍSTICOS?}

Tomando los planteamientos De Landa (2016), sostendremos que, los ensamblajes fomentan la formulación de otro tipo de explicaciones no-causales, fomenta además, entendimientos complejos sobre diversos estilos de agenciamientos que acontecen en la configuración del campo, dando cuenta de 
las diversas dinámicas heurísticas del dominio, las que ocurren en múltiples escalas, según De Landa (2016), constituyen formas históricamente contingentes cuya naturaleza describe una estructura que opera en diferentes escalas, emancipando sus formas constructivas de las clásicas dependencias jerárquicas impuestas, preferentemente, por las epistemologías normativas. Por consiguiente, sostendré que la educación inclusiva es un campo histórico, intensamente contingente, multiaxial y multiescalar. Las operatorias de los ensamblajes se construyen mediante interacciones singulares con otros ensamblajes, este mecanismo heurístico es el que sostiene la construcción diaspórica y nomadista del dominio. En él confluyen e interactúan diversas diásporas, asemejables al funcionamiento de la constelación, espacio ensamblado por elementos naturalmente heterogéneos entre sí, que no conviven de forma armónica, sino que intensamente caótica mediante aleaciones en puntos determinados.

Los principios de regulación y constitución del espacio epistemológico de la educación inclusiva son los de diasporismo -dispersión, movimiento incesante y ondulatorio- y de heterogénesis. La educación inclusiva es un ensamble, ya que se encuentra configurada por elementos heterogéneos, es un dominio cuya arquitectura acontece en el encuentro e interacción con innumerables elementos diferentes que denotan un conjunto de componentes más grandes mediante la performatividad de lo articulatorio y singulares coaliciones analíticas, políticas, éticas, culturales, económicas y metodológicas. Las configuraciones del campo "pueden acomodar ese infinito, ensamblarse y desensamblarse del que hablas usando el número indefinido de capacidades objetivas de afectar y ser afectado, y las relaciones de exterioridad que permiten la separación de componentes y su reintegración en otro ensamblaje" (Escobar y Osterwell, 2009; citado en: Castillo, 2019, p.240), regulado por un movimiento autogenerativo por sí misma. Lo flotativo es lo que hace que el cambio, la transformación y lo nuevo acontezca.

La naturaleza de configuración del campo de conocimiento de la educación inclusiva es una apertura constante a lo nuevo, comparte la afirmación de De Landa (2016), en tanto espacio intelectual que modeliza un "multiverso, en donde las partes se ensamblan y se desensamblan, y en el cual es posible señalar todos pluridisciplinares, multiescalares, translocales, no reduccionistas, heterogéneos, materialistas y procesuales (De Landa, 2016; citado en: Castillo, 2019, p.241). Esta cita confirma lo que Ocampo (2018 y 2019) sostiene, respecto que la educación inclusiva, en tanto fenómeno, no puede ser delimitado en los paradigmas de ninguna disciplina en particular, ya que su objeto desborda dichas formas heurísticas. De Landa (2016), inspirado en Morin (2008), agrega que en la actualidad ninguna disciplina se sostiene por sí misma. En ella, cada uno de los proyectos de 
conocimientos, teorías, disciplinas, métodos, discursos, conceptos, sujetos, territorios, etc., interactúan, dialogan y adoptan complejas formas de mediación y negociación, cuyos productos son sometidos a procesos de traducción epistémica y rearticulación con el objeto de alcanzar los propósitos heurísticos designados por la exterioridad del trabajo teórico, propio de las post-disciplinas. Configura un marco de conocimiento de amplio alcance por intercambio rearticulador de diversos proyectos intelectuales (post) críticos contemporáneos.

Otra propiedad epistemológica de la educación inclusiva es lo multiescalar, concepto clave en la obra de los exégetas franceses Deleuze y Guattari y en el contexto de las Américas, De Landa. Las coordenadas estructurantes del campo aglutinan elementos de naturaleza singularmente heterogéneas, agrupando entidades de diferentes escalas. Esto, es lo que, en diversos trabajos, he intentado hacer ver mediante la necesidad de aplicar el examen topológico con la finalidad de entender el lugar, la posición y los grados de proximidad y relacionamiento en escalas de diferente tipo, "en la que todos y partes coexisten como híbridos interconectados en un continuo acoplamiento y desacoplamiento" (Castillo, 2019, p.242). ¿Es la estructura, objeto y campo de conocimiento de la educación inclusiva una operación materialista? Un primer aspecto a relevar un carácter de continuo entreveramiento que genera sus propias formas.

Los ensamblajes, en tanto aparatos teóricos, nos permiten entender que ninguno de sus elementos configurantes son estableces, normativos, fijos, sino que son intensamente contingentes; piezas que no siempre se encuentran en la comodidad y en la armonía, su orgánica acontece en proximidad a las constelaciones y a los sistemas de relaciones exteriores -principio epistemológico clave de la educación inclusiva-. De acuerdo con esto denotan también una figuración próxima a la lógica de desplazados, reemplazados y rearticulados dentro y entre otros cuerpos. El proyecto de conocimiento significado bajo la denominación de educación inclusiva denota una orgánica dinámica en la que se incluyen diversas dimensiones de análisis. Su terreno analítico es articulado por un conjunto de elementos singularmente contingentes e imaginativos heterogéneos. Sus formas de ordenamiento son denominadas codificaciones, adoptan una forma particular; esto es seleccionan, componen y completan un territorio dando vida a una singular figuración heurística.

Los ensamblajes como formas de producción del conocimiento, al igual que las constelaciones -noción que discutiré en párrafos posterioresefectúan un complejo proceso de selección de los recursos epistemológicos que componen el campo de la educación inclusiva, evitando de esta forma imponer una política de todo vale, producto de la elasticidad del concepto. Su elasticidad se materializa mediante un efecto de mímesis. La educación 
inclusiva es un espacio de reterritorialización de las bases de la teoría educativa contemporánea, específicamente, instaura nuevas articulaciones devenidas en una red intelectual. La inclusión y la educación inclusiva son terrenos psíquicos, heurísticos, políticos y éticos intensamente fluidos y contingentes históricamente.

¿Qué implica pensar el funcionamiento heurístico de la educación inclusiva a través de la noción de ensamblaje? Una advertencia preliminar consistirá en evidenciar que su campo de investigación y dominio heurístico organiza su función en base a un orden de producción -leyes internas del dominio que determinan su orgánica- de carácter diaspórico y nomadista. Mediante estas articulaciones observa la convergencia y confluencia de diversos territorios y geografías del conocimiento que, a su vez, son (micro)diásporas y el resultado de otras (micro)configuraciones más complejas. El dominio de la educación inclusiva es el resultado de múltiples configuraciones más complejas, alejándose de la metáfora de la simple reunión de cosas diferentes, que hasta cierto punto, deviene en una articulación paratáctica -forma de pensar estática- y parasitaria. La educación inclusiva como fenómeno heurístico es la composición de otras muchas cosas bajo la performatividad de lo rearticulatorio, evitando la pasividad del simple amalgamiento.

La primera gran característica de su campo y objeto es significada a través de la noción de 'configuración transitoria', cuyo patrón de articulación opera en la indeterminación. Es una constelación altamente contingente e interactiva entre cada una de sus partes, en ella cada uno de sus elementos heterogéneos -principio de heterogénesis- se encuentran relacionados entre sí, por extraordinarias formas de aleación estructuradas mediante el principio de exterioridad. El componente de heterogénesis ofrece un llamamiento a una amplia diversidad de elementos, que ninguno de ellos es de la misma materia. Se observa así, una amplia infinidad de elementos, objetos, eventos, sensaciones, expresiones, signos, etc. El ensamblaje que forma es descrito bajo una figuración proximal a una combinación rearticulatoria de partes inextricablemente interconectadas. Cada uno de sus elementos es contingente, no necesariamente se encuentran conectados entre sí. Sus formas de conexión funcionan por fuera de toda serie instaurada. Así, muchos de sus elementos para De Landa (2016)

[...] pueden extraerse de un todo e insertarse en otro. "Estas relaciones implican, en primer lugar, que una parte componente de un conjunto puede separarse de él y conectarse a un conjunto diferente en el que sus interacciones son diferentes. En otras palabras, la exterioridad de las relaciones implica una cierta autonomía para los términos que relacionarse (p.10-11). 
Es un ensamblaje que, si bien, es regulado por complejas relaciones exteriores, observa, en cierta medida la participación de la filosofía de las relaciones internas, especialmente en el efecto mimético que conduce a la travestización de lo inclusivo con lo especial, devenida en la instauración de una falsa descendencia. En la interioridad de la estructura de configuración epistemológica de la educación inclusiva, ningún elemento, ningún sistema, ninguna articulación se encuentra sobre otra, toma distancia de las dependencias y de los anclajes que sostienen las configuraciones de la epistemología normativa. En contraste, su figuración analítico-metodológica se encuentra próxima al campo de múltiple escalada, evidencia un cruce multiaxial de diversas dinámicas, expresiones y mesetas. La especificidad analítica del concepto de ensamblaje heurístico nos remite a la noción guattariana de ‘agenciamiento'. Veamos ahora cómo esta noción desempeña un papel fundamental en este examen.

La educación inclusiva trabaja sobre múltiples problemas de vanguardia, no en disciplinas. Es un espacio configurado a partir de un conjunto de conjuntos conectados en algún punto. De Landa (2016), ofrecerá una precisión preliminar que no podemos omitir: el ensamblaje como agenciamiento no se fetichiza al mero acto de unir o ajustar un corpus de elementos de diversa naturaleza -actividad pasiva-, tampoco es un conjunto de partes bien combinadas, sino que describen una multiplicidad -si atendemos a los planteamientos de Rajchman (2004), observaremos que la multiplicidad es sinónimo de complejidad producto que nos conduce a múltiples articulaciones-, en ella, elementos muy diferentes entre sí establecen relaciones, enlaces y giros con la finalidad de producir algo completamente nuevo.

La construcción del campo epistemológico de la educación inclusiva, si bien explícita una amplia variedad de filiaciones, muchas de ellas actúan mediante la figura de memorias epistémicas, la emergencia de su objeto acontece por aleaciones rearticuladoras. Su arquitectura epistémica se compone de partes irregulares y no-uniformes, desempeña diversas formas de aleaciones. En contraste las relaciones internas -vínculos por descendencia- se encuentran conectadas por función y naturaleza de los términos, es decir, si los términos son lineales e íntimamente conectados validan un corpus de sistemas de extensión, aplicacionismo y partícula agregativa. Esta figuración es restrictiva para pensar el campo de problematización de la educación inclusiva, especialmente si atendemos a las formas de construcción de este saber, ya que ninguna de sus singularidades entra en contacto por su descendencia directa y naturaleza -múltiples-, forja una alianza de carácter estratégico-heurística. Las relaciones internas -sistema analítico mono-centrado- a juicio de De Landa (2016), no respetan la naturaleza heterogénea de sus componentes, acontecen en la articulación de una red analítica de carácter homogénea. En otras palabras, son patrones de compor- 
tamientos que realizan la misma función, generando el atrapamiento de los objetos y de su autenticad. Cuando estas son aplicadas a la construcción del conocimiento, sus operatorias devienen en la técnica del aplicacionismo epistémico y de la partícula agregativa. La apertura de nuevos problemas y fenómenos acontecen en la exterioridad -principio epistemológico clave de la educación inclusiva-, sí, "su "papel" dentro de un conjunto más grande no es lo que los define (esto sería una relación de interioridad). Esto significa que un componente es autosubsistente y puede ser "desconectado" de un ensamblaje y "conectado" a otro sin perder su identidad" (De Landa, 2016, p.11).

La arquitectura epistémica de la educación inclusiva y su objeto sigue la lógica de polinización descrita por Deleuze (2005), operación en la que interactúan elementos de diferente naturaleza estableciendo aleaciones contingentes. En ella ninguno de los elementos posee una relación idéntica por función o naturaleza. Es un espacio ensamblado mediante un corpus amplio de elementos de oposición que se unen mediante una singular alianza. En otras palabras, cada uno de estos elementos es opuesto entre sí, ya que se transforman mutuamente. Las formas de vinculación o relacionamientos analítico-metodológicos acontecen mediante coordenadas que asumen problemas políticos y obligaciones sociales particulares - punto conexión que reafirma su carácter sentido performativo-, es un vínculo que se crea entre diversos problemas de regulación del mundo contemporáneo. "Las herramientas cognitivas no se fusionan en una totalidad, sino que coexisten e interactuar en exterioridad" (De Landa, 2016, p.11).

El sentido inacabado de la propia educación inclusiva y su propiedad epistemológica del movimiento hace que la diversidad de elementos heterogéneos que la constituyen forme una estructura que es re-territorializados y des-territorializados permanentemente. La inclusión debe consolidarse entorno a una base heurística de carácter realista crítica clave en la inauguración de los programas de cambio. Atiende a los modos de irrupción del fenómeno, altera y transforma las formaciones del pensamiento. Reconoce que la política ontológica de la educación inclusiva es coherente con la revolución molecular. La inclusión es un signo heterodoxo, un vector de movilización de la frontera, una fuerza de alteración de las estructuras de los múltiples sistemas-mundo.

En sí misma, una singular forma de devenir es también, "un deseo afirmativo por los flujos transformadores" (Cardenal, 2012, p.20), es un vector de dislocación. También, su significante puede albergarse bajo la figuración imaginaria de reinvención, sus mecanismos de producción del deseo se fundan y persiguen la transformación del mundo -tesis número once de Feuerbach-. La inclusión "tiene que ver con el deseo del cambio y de los flujos, así como, el dinamismo de los múltiples deseos” (Cardenal, 2012, p.20). 


\section{LA INCLUSIÓN COMO FIGURACIÓN RECOGNOSCITIVA CREATIVA EN RESISTENCIA}

El programa de cambio mainstream denominado 'inclusión', demuestra un agotamiento en torno a su función de cambio e intervención en el mundo, es incapaz de remover las patologías sociales crónicas que articulan una amplia variedad de formas de miseria social. Este programa de cambio o consigna debe ser analizada dentro de los impactos que esto tiene para el mundo contemporáneo: a) la subjetividad, b) la construcción general del conocimiento, c) las intervenciones políticas y d) la práctica académica e investigativa de la educación. Otro paso, consiste en entender lo que se dice sobre ella. Coincidiendo con Braidotti (2009), en la actualidad todos los programas de cambio han agotado su función.

Lo humano siempre ha sido una categoría vinculada al privilegio y al poder -ontología sustancialista-. Sin embargo, el programa mainstream de inclusión -ratificado por todos los gobiernos a nivel mundial- define sus articulaciones ontológicas sobre un amplio abanico de dualidades, retorna aquí, la interrogante por los otros racializados, marginados y excluidos que este programa de cambio no aborda, o bien, estratégicamente los aparta de su política ontológica. La inclusión como proyecto de conocimiento no es, exclusivamente, un llamamiento alternativo, sino que, una tarea crítico-política que configura un proyecto múlti-capa y multidireccional que desplaza al antropocentrismo mientras persigue el análisis de los aspectos discriminatorios y violentos de la actividad e interacción humana donde sea que ocurran (Braidotti, 2009).

La educación inclusiva es una singular estrategia de resistencia analítica. Su terreno epistemológico y político se expresa en términos de un punto nodal en permanente mutación, es un lugar de encuentro y rearticulación, a pesar de su marcado carácter viajero zigzag, esta nunca se detiene. No persigue la activación paratáctica de cualquier teoría y debate metodológico visitado y atravesado en cada uno de sus viajes. Está más interesada en su transformación, sus operatorias acontecen en la performatividad de lo rearticulatorio. ¿Qué es lo que define la inclusión en tanto proyecto de resistencia? Un aspecto medular por rescatar es la potencia analítica de la interseccionalidad en cada uno de recursos epistemológicos confluyentes, operación que va en contra de las expectativas de una gran teoría devenida en un espacio heurístico fuera de lugar desde el que no entendemos el uso de la teoría.

La configuración de las formas constructivas de este campo sugiere un examen sobre sus contingencias históricas y políticas -ambas nociones se interpenetran constantemente en el estudio de sus condiciones de producción-. La inclusión como proyecto de resistencia enfrenta un dilema definitorio fundamental, esto es, analiza las relaciones de poder estructurales y las 
representaciones culturales que interroga. Otro dilema analiza cómo determinados cuerpos de conocimientos establecen alianzas imperceptibles al servicio de la desigualdad, la dominación y la opresión. Asimismo, cómo el conocimiento influencia la configuración de las relaciones de poder, confirma la aleación de sus enunciados con una de sus memorias epistémicas: la interseccionalidad crítica.

La inclusión como proyecto de conocimiento atiende significativamente a las relaciones de poder y a las desigualdades sociales que afectan y permean las reglas institucionales de funcionamiento de la sociedad y del sistema educativo en su conjunto. Al concebirse como estrategia analítica proporciona nuevos ángulos de visión sobre la heterotopicalidad de fenómenos albergados en su interioridad. Construye una praxis crítica que informa acerca de diversos proyectos de justicia educativa. A pesar de que el interés por el campo ha crecido aceleradamente, sus esfuerzos siguen estando en una reproducción imperceptible y dramática.

La interrogante que impone la afirmación: educación inclusiva como proyecto de conocimiento en resistencia, analiza los espacios y las formas de interpenetración y rearticulación a través de los cuales este enfoque se ha ido configurando 'a través', 'más allá', 'por fuera', e incluso, en contra de singulares espacios políticos y regionalizaciones heurísticas. Tal empresa, sugiere una advertencia preliminar, esto es, fortalecer los niveles de alfabetización teórica, política y metodológica requerida por el dominio. La singularidad constructiva del dominio, fomenta que ninguno de sus campos convergentes actúan rígidamente separados, más bien, la configuración de su estructura de conocimiento describe un proceso centrifugo, que viaja y se moviliza por diversos lugares, pasando por campos disciplinares, interdisciplinares y post-disciplinares -territorio de múltiples convergencias epistemológicas entrecruzadas-, se adapta a diversos campos discursivos y de investigación, ratificando el carácter flexible de su operatoria heurística. Interrogando la pregunta, la inclusión se convierte en un deseo y a su vez, en una percepción crítica que fomenta nuevas lecturas sobre las singulares formas de regeneración y acción performativa del poder, es un fenómeno en construcción recíproca que opera por intimidad crítica, esto es, establece planos de cercanía entre lenguajes y formas teórico-metodológicas que participan en su construcción. A pesar de este consenso general, las definiciones de lo que cuenta como ‘inclusión’ y ‘educación inclusiva' están lejos de ser claras.

En la actualidad, se observa un ajuste del significante mainstream de la inclusión a diversos formatos de investigación, es decir, a un conjunto de metodologías estándares que, en el caso de las Ciencias de la Educación, refieren a los métodos y metodologías generales proporcionadas por las Ciencias Sociales. Aquí, emerge otro nudo crítico, las Ciencias de la Educación 
no poseen un método propio de investigación, con niveles y grados debidamente formalizados. Esta empresa o tales grados de decisiones lo que buscan es promover la formalización y adecuación por abducción -no rearticulación- los fundamentos de la educación inclusiva -intrínsecamente ligados a la imposición y travestismo de la educación especial -escandalo epistémico persistente- dentro de determinados campos y regiones de estudio e investigación. Tal operación trabaja a través de una modalidad extensiva o de partícula agregativa, extiende su alcance dentro de determinados campos, entonces se observa la presencia de investigaciones que, previamente no han sido informadas de la base heurística y metodológica de la educación inclusiva. El calificativo opera en términos de algo que camina y viaja alrededor de diversos campos de estudio. La confluencia de sus campos de estructuración tampoco es tan evidente dentro de la comprensión de su aparato cognitivo. ¿Cómo se sintetiza este proyecto de conocimiento en diversos campos de estudio e investigación?

La inclusión como proyecto de conocimiento en resistencia a pesar de construir una espacialidad analítico-metodológica que opera e inscribe su tarea heurística al margen, es escéptica a la aplicación de metodologías propias de campos disciplinares, no es dada a la integración de teorías y métodos convencionales aplicados por diversas geografías epistémicas. En tal caso, toda forma metodológica podrá ser rearticulada, más bien, busca la integración de ideas innovadoras y críticamente transformativas permiten examinar-de-otro-modo la realidad y la diversidad de problemáticas de los sistemas-mundo. Su accionar metodológico y analítico se encuentra próximo a la noción 'sobre legible', esto es, una posición de lectura e interpretación basada en una multiplicidad de sentidos, niveles, sujetos y líneas argumentativas.

La inclusión como proyecto de conocimiento sintetiza herramientas de navegación analítico-políticas para pensar acerca de su naturaleza y su rol en el mundo contemporáneo. Este punto es clave, puesto que, tensiona el sentido de la función educativa. Al constituir un proyecto de conocimiento de base amplia, denota un ensamblaje dinámico que proporciona nuevos ángulos de visión sobre prácticas y problemas determinados que no solo bordean el orden de las injusticias, sino que más bien, el de las imaginaciones desafiantes que erigen y sustentan un mundo-de-posibles, evaluando si su red objetual constituye o no, un performativo (des)afortunado. Es, a su vez, un singular proyecto que informa y nutre su red analítica a través de diversos marcos proporcionados por la justicia, las teorías feministas, los estudios culturales anglosajones, latinoamericanos y asiáticos, los estudios post- y decoloniales, los estudios de la mujer, los estudios de la subalternidad, los estudios críticos de la raza, la interseccionalidad política y estructural, la interculturalidad crítica, la pedagogía crítica, los estudios queer, los estudios de género, la filosofía de la diferencia, etc. 
La pregunta por el corpus de elementos que definen la inclusión como proyecto de conocimiento en resistencia, atiende a los ejes de producción de un nuevo conocimiento, hablamos así, de una relación imbricada e interpenetrada entre proyecto de conocimiento y estrategia analítica. Un proyecto de conocimiento en resistencia se construye en la intimidad analítica de las relaciones entre conocimiento y poder, proporcionado lenguajes, conceptos y teorías para interpretar la inclusión como un contra-punto reflejo de singulares relaciones de poder performativas. La inclusión es algo que se construye social y políticamente, se legitima en la micropráctica.

¿Cuáles son los conocimientos y formas metodológicas ligadas a un proyecto epistémico de resistencia? La misma interrogante podría efectuarse en la dimensión política del proyecto. Es un conocimiento que está informado e influenciado por particulares relaciones de poder -de ahí, la necesidad de efectuar un análisis relacional de las problemáticas del campo, las que pueden ser aplicadas a la construcción de políticas públicas en la materia-. El objeto de análisis de la inclusión centra su foco analítico al interior de las variables que condicionan la relación recursiva entre estructuras sociales y representaciones culturales. Se interesa por analizar el conjunto de significados interconectados situados por la opresión, la dominación, la injusticia y la desigualdad atendiendo lo que esto hace con la subjetividad de cada sujeto-ciudadano, todas ellas, expresiones de naturaleza regenerativa y performativa, articulan patrones específicos de ubicación de diversos colectivos de ciudadanos. La lucha en contra de cada una de estas formas crónicas de regulación social y educativa, se encuentran en el corazón mismo del proyecto de resistencia.

El entendimiento de la opresión, la dominación, las injusticias y la desigualdad son puntos medulares, junto al ideal de transformación, en la construcción de la teoría de la educación inclusiva. Otra singularidad de este proyecto deja espacio para un amplio número de colectividades y comunidades de adherencia e interpretativas, vinculando una variedad de proyectos de conocimiento específicos. Una de las principales obstrucciones analíticas asume un análisis monocentrado y monocategorial para estudiar las injusticias y la desigualdad, etc, descuida un análisis en torno a las formaciones sociales y proyectos de conocimiento que reproducen tales formas de desigualdad. La inclusión como proyecto de conocimiento opera mucho más allá de un sistema mono-analítico. En efecto,

[...] también se puede conceptualizar de manera rentable como una constelación de proyectos de conocimiento que cambian en relación entre sí en conjunto con los cambios en las comunidades interpretativas que los adelantan. El proyecto de conocimiento más amplio proporciona un conjunto de ideas que proporcionar momentos de consenso definitorio (Hill Collins, 2015, p.9). 
La inclusión como estrategia analítica entraña una doble función. La primera, construye una forma particular de analizar problemas, fabrica una táctica epistemológica para abordar una amplia variedad de problemas educativos de carácter complejos. También, puede ser concebida como una matriz de "investigación analítica, más que una alineación o prescripción específica para enfoques o técnicas metodológicas particulares" (Burman, 2017, p.12). Mientras que, su segunda función, la sitúa en relación con la producción de nuevos conocimientos sobre el mundo educativo, social y político, permitiendo emplear la noción de formas diferentes.

Tomando de Hill Collins (2015), la noción 'sensibilidad analítica', sostendré que lo que hace que el análisis que prolifera por vía de la inclusión sea inclusivo, escapa al uso del propio término, sino que crea formas de figuración creativa no-dialectal que ofrecen salidas para "pensar sobre el problema de la igualdad y la diferencia y su relación con el poder" (Cho, 2013, p. 795). La dimensión analítica de la inclusión como nueva praxis heurística funciona cuando la vemos. Sin duda, un examen sobre los patrones de producción de un nuevo conocimiento puede ser algo mucho más productivo en la comprensión de la inclusión, específicamente, enfrenta la interrogante por el corpus de temas qué caracterizan la inclusión -cierto consenso existe que estos se inscriben más allá de la discapacidad y la lucha por la justicia-, o bien, ¿qué preocupaciones e intereses comparte este trabajo con otros proyectos de conocimiento? El trabajo teórico y constructivo de la educación inclusiva posee muchos matices significativos en la transformación del mundo contemporáneo. Por esta razón, al concebir su fuerza analítica en términos de un 'punto nodal' y un 'mecanismo de transposición heurística' para la teoría educativa contemporánea, es clave para la concreación de un enfoque relacional que atraviesa formatos teóricos y corpus metodológicos. La inclusión produce otras ideas epistemológicas, entiende que los nuevos conocimientos y formas metodológicas que esta produce no son neutras y ni se encuentran fuera de relaciones del poder, más bien están profundamente imbricados en ella.

Entre los principales desafíos epistemológicos que enfrenta, destacan: a) su conocimiento no es políticamente neutral, b) su trabajo empírico debe considerar los presupuestos orientadores de su praxis, de lo contrario sucede lo que hasta ahora ha hecho el maistream de su discurso, "mantener sin darse cuenta las mismas desigualdades sociales complejas que pretende comprender" (Hill Collins, 2015, p.14). Este ha sido mi objetivo investigador durante algunos años, específicamente, cuando refiero a la necesidad de comprender cómo operan las estructuras escolares y sociales, así como los mecanismos de funcionamiento de cada uno de los formatos del poder, es decir, diversas expresiones de naturaleza regenerativa y performativa. Bajo este concepto se aglutinan la injusticia, la opresión, la dominación, la indiferencia 
colectiva, la desigualdad estructural y micro-escalar, la violencia estructura y silenciada, etc. Todas ellas, interrelacionadas e interpenetradas profundamente. Así,

[...] las personas y los grupos colocados de manera diferente dentro de los sistemas de poder que se cruzan tienen diferentes puntos de vista sobre sus propias experiencias y las de los demás con complejas desigualdades sociales, típicamente avanzando en proyectos de conocimiento que reflejan sus ubicaciones sociales dentro de relaciones de poder (Hill Collins, 2015, p.13).

Finalmente, observo la coexistencia de una política de desigualdad acerca de cómo los investigadores y profesionales del campo utilizan el sintagma educación inclusiva, reflejando diferentes grados de énfasis en análisis específicos, ratificando una utilización funcional. Frente a esto, surge la necesidad de explorar en qué medida estas formas analíticas y de trabajo, contribuyen a clarificar los contornos teóricos del campo y a develar sus supuestos heurísticos subyacentes. Coincidiendo con Hill Collins (2015, p.16) es altamente necesario situar la comprensión epistemológica de la educación inclusiva, a través de

[...] la construcción de articulación de Stuart Hall lo que puede resultar muy útil para examinar los patrones dinámicos de cómo los académicos usan la interseccionalidad como estrategia analítica. Hall plantea que una teoría de la articulación es "tanto una forma de entender cómo los elementos ideológicos, bajo ciertas condiciones, se unen en un discurso, y una forma de preguntar cómo se articulan o no, en determinadas coyunturas, a ciertas luchas políticas (Grossberg, 1996, p. 141-42).

\subsection{Principales características de la educación inclusiva como proyecto de conocimiento en resistencia}

Los problemas y desafíos epistemológicos de la educación inclusiva en los que me intereso intentan comprender los mecanismos de afectación no sólo sobre el uso del término, sino que, exploran su función intervencionista en el mundo contemporáneo. Me interesa explorar las figuraciones alterativas que acontecen por fuera de las exigencias canónicas de la investigación. La inclusión en tanto proyecto de conocimiento en resistencia persigue el deseo de justicia social y la transformación progresiva introduce otros sistemas de razonamientos producto de interpenetración de los legados del feminismo, la interseccionalidad, la filosofía de la diferencia, los estudios culturales asiáticos, los estudios de la mujer, los estudios queer y de género, los estudios post- y decoloniales, etc. Ante el agotamiento de los programas 
de cambio, la inclusión, emerge como una figuración creativa y alterativa de la realidad, un dispositivo de esperanza renovada, una estrategia de reforma social de carácter relacional que opera en las intersecciones zigzag de lo macro y microestructural. Si el deseo de la inclusión persigue la producción de lo nuevo, entonces, deviene en una figuración que activa un espiral de profundos cambios. Es signo de un desafío abierto y un vector de disipación heurística que trabaja en la creación de una noción diferente de responsabilidad ética que reconfigura al ser, no se limita solo al encuentro con este. Construye nuevas figuraciones o modos de imaginar diferentes marcos de pensamiento sobre lo político, lo social y lo educativo.

La epistemología de la educación inclusiva ejecuta un corpus de cambios alterativos en la forma de leer y de aproximarnos a una red de fenómenos, denota una operación abierta, inquieta, afirmativa de carácter no-dialectal e intensamente creativa. También, puede ser concebida como una morfología heurística dinámica ensamblada por intensos flujos, una red de apertura, creación y relación de diversas singularidades heterogéneas -principio de heterogénesis-. Es algo que trabaja en la cuestión epistémico-óntica del 'llegara-ser', un movimiento que nos conduce a una etapa superior de realización es un dominio en permanente construcción. Rescata la pluralidad epistemológica, imputa un corpus de puntos de fuga que afectan las formas de pensar y a sus usos heurístico-políticos. Entre las principales características que definen la inclusión como proyecto de resistencia, destacan:

- La inclusión en tanto categoría de análisis participa de las relaciones de poder y de las representaciones culturales y políticas que interroga. Atiende significativamente a las formas que hacen que su conocimiento sea comprensible y aplicable a los problemas del mundo actual.

- La inclusión en tanto estrategia política, construye singulares mecanismos para descolonizar el inconsciente. No sólo trata de poner en práctica diversas clases de derechos, sino que su racionalidad permea la vida de las personas y sus formas de relacionamiento y subjetividad, más allá del problema antitético del derecho a la redistribución y a la diferencia.

- La inclusión a nivel estructural reclama una acción performativa, se encuentra inextricablemente vinculada al análisis de las lógicas de funcionamiento del poder, cuyo énfasis va más allá del estudio de las estructuras de desigualdad.

- La inclusión es un movimiento deconstructivo-transformacionalcreativo. Se propone reconocer las formas de resistencia, haciendo ver qué cosas el trabajo crítico en este campo ha omitido. Para ello, es fundamental desafiar las aceptaciones acríticas del término, poniendo en evidencia el conjunto de prácticas en las que el 
discurso y su trama argumentativa conducen a fantasías coloniales y capitalistas sobre la diferencia y la singularidad.

- La epistemología de la educación inclusiva es un comentario performativo, como tal se interesa por recomponer sus alcances en el mundo académico y político. Construye una nueva forma de intervención práctica y un dispositivo de producción de la subjetividad singularizante.

- La política del contenido teórico en su mayoría avanza por esfuerzos nómades y diaspóricos entre diversos proyectos de conocimientos, formas metodológicas, teorías, compromisos políticos y éticos, conceptos, (inter)disciplinas, territorios, etc. De ninguna manera, intenta ubicarse en proximidad a la metáfora de obscenidad de los campos abiertos. La educación inclusiva es un proyecto de conocimiento que trabaja al margen y desde los márgenes con cada uno de sus aportes convergentes.

- La inclusión como proyecto de conocimiento en resistencia deshace y trasciende los sistemas de otrificación, esto es,

[...] al centrarse y reafirmar la identidad en las categorías de raza, lengua y nación, se prolonga hasta nuestros días, a veces en la buena voluntad de celebrar la diversidad y la hibridez; y otras, en la acentuación 'orgánica' de esa misma diferencia para legitimar discursos excluyentes y -en su lado más oscuro- racistas (Cho, Crenshaw \& McCall, 2013, p. 789),

imponiendo un conjunto de esencialismos-individualismos que obstruyen el acceso a su comprensión epistemológica y singularidad contextual y política en el mundo actual.

Al reafirmar la educación inclusiva un campo ensamblado por silenciosas formas de individualismos-esencialismos, enfrenta el desafío de avanzar en la subversión de

[...] un tipo de diferenciación que en última instancia es aditiva o método acumulativo, que requiere que otros se nombren como otros mientras retener el término genérico como la cuadrícula de inteligencia general, la morfología que tiene el poder de dar cuenta de adicionales, incluidos divergentes o desviados (Cho, Crenshaw \& McCall, 2013, p. 792).

\subsection{Especificidades en la construcción de un proyecto de conocimiento en resistencia}

La naturaleza post-disciplinar de la educación inclusiva describe un fenómeno que no puede ser delimitado en los paradigmas de ninguna de las disciplinas y proyectos de conocimiento que colaboran en su configuración. Su objeto, 
campo y dominio emergen en la exterioridad del trabajo teórico, es decir, escucha y fabrica su corpus de conocimiento 'más allá' y 'por fuera' de sus aportes convergentes. La exterioridad constructiva del territorio hace que muchas personas ubicadas dentro del campo educativo así como algunos fuera de estos lenguajes y confines analíticos y metodológicos mal entiendan sus demandas y contornos. Lo mismo sucede cuando se afirma que la inclusión no posee método, inferir por completo esta acción puede conducir a ciertos errores. Es claro su halo de ininteligibilidad al respecto. Cuando afirmo que los desarrollos intelectuales de la educación inclusiva no demuestran un método claro, sostengo que esta carece de una forma analítica propia que traza los nortes de la investigación y de la formación de sus educadores, así como, el tratamiento de cada uno de sus fenómenos. Me interesa ser consciente de la amplia variedad de confluencias y convenciones epistémico-metodológicas que se entrecruzan, interconectan en zigzag y desfiguran -entiéndase como una acción que produce otra cosa- el campo educativo en tanto sistema de transformación de la experiencia. Esta multiplicidad de elementos no tiene por qué imponer un signo de borradura sobre los temas más candentes sobre cuales la inclusión llama la atención en el mundo contemporáneo, intensifica la sofisticación de sus formas de análisis y constructividad.

Sus múltiples formas de vinculación no siempre son aparentes. Los esfuerzos para producir nuevos conocimientos no pueden dispensar con los aparatos a través de los cuales se produce la información, se clasifica, e interpreta. La inclusión como proyecto de conocimiento no se ubica dentro de ningún marco específico. Se interesa por abrir nuevas vías de pensamiento -signo de movilización de la frontera-. Su heurística no trabaja exclusivamente interrogando las lógicas institucionales del conocimiento y de la investigación, o en contra de la norma. Ciertamente, atiende al conjunto de imbricaciones imperceptibles en las que su objeto interactúa con proyectos de conocimiento propios de la desigualdad. En tanto forma epistemológica, trabaja en la creación de su propia metodología de análisis. ¿Qué quiere decir esto? Crea un espacio analítico, político y discursivo de otro modo, que opera por fuera de lo habitual -heterológico-, evitando la obstaculización de un campo insurgente como el aquí analizado. Otro punto crítico es su nula alfabetización metodológica y epistémica, es un terreno de radialidad cuya operación heurística no acontece a través de cada uno de sus recursos constructivos confluyentes, sino en una acción dialectal singular no-hegeliana, compleja e inquieta. Es un campo que informa a otros campos y es informado por muchos territorios divergentes -ensamblaje-.

De acuerdo con la singularidad de la naturaleza del conocimiento de la educación inclusiva, es posible definir sus contornos metodológicos en términos 'sensibilidad analítica' - concepto que tomo prestado de Cho, Crenshaw \& 
McCall (2013) y Hill Collins (2015)-. ¿Cuáles son las implicancias de la sensibilidad analítica en este terreno constructivo? Fundamentalmente, fomenta una comprensión del fenómeno en tanto disposición del pensamiento, es un vector de imaginación e intervención alterativa en los sistemasmundo, las relaciones, formas y coordenadas de la igualdad y la equidad con el problema de la diferencia. También puede ser descrita en términos de una forma analítica permeable, inquieta y en constante búsqueda.

La epistemología de la educación inclusiva es un esfuerzo por pensar y especificar de otra forma las relaciones educativas, sus pasiones y afectividades. Sensibilidad que choca con las formas de educacionismo teórico-metodológico legitimadas. También es concebida como un esfuerzo teórico-político para pensar críticamente sobre ciertas condiciones que menudo implican un compromiso activo con las convenciones analíticas y sus categorías, muchas de ellas integradas en el lenguaje, sus formaciones metodológicas, relacionamientos, pasiones, etc.

Una de sus preocupaciones metodológicas consiste en deslindar el reduccionismo epistémico de sus planteamientos débilmente instaurados. Se propone, además, construir una forma metodológica capaz de capturar la complejidad y la multidimensionalidad de las expresiones del poder y su marca en la trama subjetiva de las personas. Sus compromisos políticos van más allá de la puesta en práctica de derechos, inaugura una racionalidad única para entender las actuaciones de la igualdad, la justicia, la equidad, etc. Aboga por una visión alternativa sobre la subjetividad, la ética y la emancipación, al tiempo que se opone a los principios del individualismo liberal.

El potencial de la inclusión en el mundo contemporáneo reside en su aplicación brillante y rigurosa sobre cada uno de sus tópicos de análisis, más que en el rechazo teórico, el reemplazo, la reducción y la remediación, todas ellas formas analíticas canónicas. La construcción del campo epistemológico de la educación inclusiva no se centra en ninguna forma teórica y metodológica particular, tampoco inscribe su fuerza de trabajo en una acción antitética. Más bien rescata sus legados y tradiciones concebidas como poderosas formas de intervención alterativas del mundo y de sus estructuras. Mi interés investigador dedicado al estudio teórico y metodológico de la educación inclusiva puede ser concebido como un intento por des-habituar y deslindar las figuraciones y sus significantes que sitúan su tarea en términos de una afirmación general y una concepción política simplificada extremadamente arraigada en el mundo contemporáneo.

La inclusión a pesar de viajar por diversos espacios y discursos demostrando que su política de producción del conocimiento se encuentra lejos de ser considerada un proyecto insurgente y transformador, enfrenta el desafío de aclarar "la forma en que se reciben, historizan y se comprometen tales proyectos. Tanto las ideas en cuestión como las respuestas que generan las 
ideas insurgentes reflejan relaciones estructurales que están dinámicamente constituidas por las mismas fuerzas siendo interrogadas" (Cho, Crenshaw \& McCall, 2013, p. 798).

Sin duda, la pregunta por las condiciones de producción -imbricaciones entre lo político, lo histórico y lo social- fomentan una comprensión de sus múltiples puntos críticos de interreferenciación establecidos dentro y fuera de sus formaciones institucionales que inciden en la producción de sentidos sobre aquello que se entiende por inclusión, así como, por sus fijadores de convenciones discursivas y métodos reconocibles.

Fomenta además, un examen acerca de las formas intelectuales adoptadas en el campo en su devenir, comprendiendo como esta ha sido empleada para pensar diversas problemáticas en su paso y vinculación con diversas regionalizaciones epistémicas. La inclusión es un concepto altamente productivo aplicándose a una infinidad de contextos y campos de trabajo. Como proyecto de conocimiento opera de manera expansiva estableciendo diversas formas-de-lo-posible, se convierte en un dispositivo de imaginaciones desafiantes que interfieren e irrumpen diversos compromisos intelectuales. Es un territorio compuesto por diversos segmentos teóricos, conformados por diversas cuestiones políticas. ¿Cómo es la puesta en práctica de la inclusión? La inclusión se plantea un sinnúmero de preguntas sobre diversas cuestiones críticas que tocan y tensionan nuestro presente.

\section{LAS ‘TRANSPOSICIONES' Y EL 'MOVIMIENTO' COMO CONDICIONES DE PRODUCCIÓN DEL CONOCIMIENTO DE LA EDUCACIÓN INCLUSIVA}

La fuerza teórica que reside en la 'transposición' en tanto herramienta heurística denota una singular operación constructiva de transferencia analítico-metodológica de carácter transfronteriza. Para Braidotti (2002) las transposiciones fomentan un salto de código, lenguaje, campo y aparato metodológico hacia otro lugar o rumbo. Desde mi posición teórica, no es un salto que da lugar a una pluralidad de cosas, sino que es una operación fundada en la heterogénesis, que trans-codifica, mueve elementos, los descentra, los superpone y los traduce para configurar una nueva forma. La heterogénesis en esta regionalización opera en términos de multiplicidades complejas de recursos convergentes, distanciándose de la mera paleta de colores que impone el signo de lo diverso -artificialidad e instrumentalismo analítico-.

Las transposiciones en tanto herramientas epistemológicas aplicadas a la recognición del dominio no se reducen a la mera cuestión de tejer diferentes hilos, variaciones sobre un tema, sino, más bien, sugiere una escala de variaciones y cambios en un patrón discontinuo y armonioso. El dominio de la educación inclusiva deviene en la creación de "un espacio intermedio de zigzag y de cruce: no lineal, no, pero caótico; nómada, pero responsable 
y comprometido; creativo, pero también cognitivamente válido; discursivo y también materialmente incrustado, es coherente sin caer en la racionalidad instrumental" (Braidotti, 2002, p.13).

Las transposiciones en términos heurísticos aluden a un singular proceso de mutación, transformación y alteratividad del orden cotidiano de las cosas. El objeto y dominio de lo inclusivo es un fenómeno transposicional, espacio regulado y construido por diversas formas de transferencia de información que no acontecen de forma lineal, ni aleatoria, ni arbitraria, sino "en oposición a la visión científica dominante que tiende a definir el gen como una entidad estable que transmite unidades fijas de herencia en un manera autónoma y autosuficiente" (Braidotti, 2002, p.14).

La potencia de las transposiciones en la construcción del conocimiento acontece en términos de multiplicidad y complejidad, articulan un espiral de niveles de constructividad, su fuerza expande un repertorio de ideas, acciones y recursos constructivos, descentrado y trans-codificando cada uno de ellos. Su marcado carácter transposicional no niega la multiplicidad de formas epistemológicas convergentes, más bien, las mantiene interconectadas en planos reticulares y en múltiples capas, atendiendo a su singularidad.

\subsection{Inclusión como teoría y epistemología nómada: el devenir como punto constructivo y de emergencia}

La inclusión como teoría nómada sugiere la configuración de un contra-punto epistemológico. Es una singular forma teórica en devenir, su transformación depende de procesos de subjetivación que atraviesan sus mecanismos de enunciación del saber. La fuerza constructiva de lo nómade a juicio de Braidotti (2004)

[...] refiere a un tipo de consciencia crítica que se niega a situarse en los modos y prácticas sociales codificadas" (p.216). Para la célebre filosofa italo-australiana, Rosi Braidotti, tales mecanismos pueden ser concebidos "como figuración de la subjetividad contemporánea, el nómade es pues una entidad postmetafísica, intensiva, múltiple, que se desenvuelve en una red de interconexiones [...]. Una de sus tareas históricas es descubrir cómo recuperar un sentimiento de intersubjetividad que permita el reconocimiento de las diferencias para crear un nuevo tipo de vínculo de una manera inclusiva (es decir, no excluyente) (Braidotti, 2000, p.78).

Su heurística se basa en el entrecruzamiento e interconexión de diversas teorías y proyectos de conocimiento, da vida a un signo en permanente devenir. Lo que define a la inclusión como un proyecto de conocimiento 
en resistencia es el conjunto de contra-saberes que aglutina en su paso por diversas regionalizaciones.

La epistemología de la educación inclusiva atraviesa una amplia variedad de proyectos de conocimiento, contribuye a la afirmación de un nuevo modo de subjetivación que comporta la imbricación de lo epistemológico y lo político -aspecto clave en esta comprensión heurística-. El pensamiento nómade genera nuevas prácticas interpretativas devenidas en nuevos sujetos y cartografías del saber. Si bien transita por diversos proyectos críticos de conocimiento, no se queda allí, su operación cognitiva acontece en el giro y en la rearticulación. Una de sus opciones ontológicas consiste en concebir al sujeto de lo inclusivo como parte de lo anti-esencialista y lo posthumanista. Las teorías nómadas conjugan una serie de elementos políticos y un conjunto de devenires y lugares otros para la construcción del saber. Inauguran un espacio intelectual en permanente contradicción. El horizonte heurístico de lo nómade inscribe su potencia creadora más allá de lo establecido, centraliza su fuerza en la dispersión, lo múltiple, lo interconectado, etc., aquello que opera en constante flujo entre cada uno de sus diversos elementos constructivos.

El dominio de lo inclusivo es un espacio en el que se incardinan mundos diversos, cada uno de los cuales se encuentra superpuesto entre varias mesetas de la realidad. Es un signo cuyo despliegue acontece en la exterioridad, es una entidad móvil que perdura a través de diversos conjuntos de variaciones discontinuas. El pensamiento educativo es siempre nómade, se encuentra en permanente devenir. Lo que le interesa a este tipo de construcción teórica es el proceso de volverse teoría. Para Braidotti (2006), las teorías nómadas establecen una red analítica no-jerárquica, fundamentan su actividad en la construcción de contra-sentidos y contra-saberes. La sección del sintagma 'contra' no sugiere una operación negativa, más bien, se propone crear nuevas prácticas sociales y una nueva cartografía del saber. En esta comprensión el sujeto y el saber son acciones del poder. Todos ello, sugiere nuevas modalidades de construcción heurística que obligan a trazar una nueva cartografía, nos conduce no sólo a la clarificación de su cuerpo de saberes, sino también, a una nueva política de imaginación epistémica, a una forma de apropiación del ser y a una afectividad que deforma el mundo.

La producción del saber de la educación inclusiva se encuentra estrechamente ligada al tejido intersubjetivo, es un saber y un marco comprehensivo hacia la creación de un singular proceso de creación de lo posible. Las teorías nómades son el resultado de un conjunto de prácticas analíticas, metodológicas, políticas, éticas y discursivas, que al intentar encontrar su índice de singularidad lo hacen a través de la rearticulación. El saber de la educación es siempre situado, dinámico, intersubjetivo y complejo. Los dispositivos de subjetivación singularizante incluyen la historia. En ella, 
el desafío por la inclusión es convertir su espacialidad crítica en tipos distintos de hegemonías disruptivas que siguen la lógica del punto-de-fuga. El movimiento como propiedad epistemológica de la educación inclusiva es concebido en términos de una determinación inestable, no queda delimitada exclusivamente a lo cambiante, sino que, instituye un proceso de construcción de poderes que se adaptan al contexto de subjetivación.

El campo de producción de la educación inclusiva puede ser descrito términos de grieta, esto es, un conjunto de desplazamientos en diversas direcciones, cuya transitividad es analogable a la operación de Braidotti (2006), respeto del viaje "de las teorías y movimientos anticoloniales hacia una crítica postcolonial; luego, del feminismo hegemónico heterosexual y colonial hacia una crítica de la construcción transversal de la raza, del sexo, del género y de la sexualidad" (Cabrera y Vargas, 2014, p.28). Su arquitectura heurística es significada en tanto espacio de profundas especificidades contextuales, fomentando según Braidotti (2006)

[...] reconocer la parcialidad de las enunciaciones científicas, su necesaria contingencia, su dependencia de mecanismos concretos que están muy determinados por factores históricos y socioeconómicos, no tiene nada que ver con el relativismo. Antes bien, es una actitud que marca un cambio significativo en la ética del estilo discursivo e intelectual. Que se repudie el universalismo anticuado para prestar mayor atención a la complejidad de los «saberes situados» augura una mayor flexibilidad en la investigación, especialmente en el campo de las humanidades, así como, una nueva sensibilidad ante las diferencias (Braidotti, 2000, p.209).

Al concebir la inclusión como una teoría nómada, su fuerza analítica impone un proyecto de intensidades críticas y creativas, sitúa a las personas en posiciones de subjetividad discursivo-política. Su nomadismo epistemológico sugiere una transformación sustancial de cuatro de sus características medulares de su territorio: a) sustituir la idea de diferencia por singularidades múltiples, b) recognocer el sentido intrínseco de la inclusión como categoría de análisis y aparto político contingente que perfoma las estructuras de configuración de los sistemas-mundo, c) su arquitectura epistémica se compone de saber mutante, instable y en permanente evolución. La inclusión en tanto teoría nómada "se desplaza en los intersticios, los intervalos, a la frontera entre todos los espacios estructurados. Es un pasador capaz de crear analogías, puentes entre varias mesetas distintas. Rechaza la idea de todo lo que es establecido, fijo, inmutable y proveniente de un poder uniformizador" (Palaisi, 2018, p.66). 


\subsection{Inclusión como teoría en permanente viaje y transposición}

¿A qué metáfora del viaje adscribe la educación inclusiva? La metáfora del viaje no sólo atañe a la singularidad de los movimientos que definen parte de su espacio migratorio, sino más bien, su potencial heurístico se juega en la creación de categorías críticas que fomentan la emergencia de nuevas prácticas, ideas, sentidos y sentires. La comprensión del dominio de la educación inclusiva exige atender a las formas en las que viajan las teorías y las ideas en su interioridad. En este incesante movimiento cada una de ellas va mutando, transformando, dislocando, y resignificando sus elementos de constitución y aleación. La base de las teorías viajeras se alberga en un conjunto de micro-movimientos alterativos, orquestados trasrelacionalmente. La convergencia de cada uno de estos en su estructura superficial parece estar interconectados, mediados, informados y afectados por singulares circunstancias históricas. En la interioridad del campo observo la circulación de palimpsestos epistémicos, es decir, elementos que nunca podrán borrarse, residuos y formas de originalidad que mutan. Ninguna de las formas estratégicas del campo, al transformarse, sustituye su originalidad, no se vuelve dócil sino que irrumpen con mayor fuerza desestabilizando un aparato falsificado o mimético.

El dominio de la inclusión no domestica ninguna teoría, sino que las traduce y las redobla creando un efecto de co-producción múltiple y trasrelacional. Es difícil situar un consenso acerca de las teorías que confluyen en la estructuración de su dominio, especialmente al ser regulado por el principio de la heterogénesis. Es un dominio dinámico y a-centrado, cuyas formas teóricas se emplean para subvertir y perturbar el lenguaje del patriarcado cognitivo, especialmente, en sus formas opresivas y esencialistas. El trabajo heurístico acontece en un lugar claramente definido 'en relación', 'más allá' y 'por fuera' de diversos campos de estudios que convergen en la configuración de su dominio. Es concebido como un acuerdo que inaugura un lugar aceptado, ofrece desafíos distintos para muchas posiciones establecidas en y alrededor de estudios sobre educación inclusiva. Asume una conciencia epistémica compleja, íntima y altamente sensible ante una variedad de complejidades a diversas problemáticas interconectadas de clase, feminismo, etnicidad, historia, injusticia, política, relaciones éticas, atravesadas por una red de enredos genealógicos imbricados y las líneas de fuerza que han constituido y estructurado su relación con cada uno de estos campos.

El traslado de una teoría a otra puede ocasionar singulares formas de contaminación e incluso, distorsión de su sentido. En efecto, tal como indica Said (2000, p.12), "el reconocimiento crítico de que no existe una teoría capaz de cubrir, cerrar, predecir todas las situaciones en las que podría ser útil”. En este punto, me parece oportuno recurrir a las formas de traducción. 
¿Cómo entender este mecanismo? El campo epistemológico de lo inclusivo se conforma por elementos que viajan por voluntad propia y otros que no. No son sólo estos elementos los que permiten desarrollar una comprensión situada acerca de la función de regulación constructiva del campo. Gran parte de cada uno de los recursos que dibujan su dominio auténtico, son objeto de una compleja acción de violencia epistémica. La seguridad en el desplazamiento siempre está dada por complejas y singulares formas de traducción, mediación, negociación, entre otras, que operan en términos de un complejo sistema de intermediación y una zona de contacto. ¿Desplazados o viajeros? Los recursos epistemológicos de la educación inclusiva no pueden ser estrictamente concebidos en términos de desplazados ya que poseen un marcado sentido de identidades, el movimiento no es significado en términos de huida, sino de viaje, de algo que se impulsa a ver otras formas de visualidad, comprensión del fenómeno y de sus estrategias de regulación.

Las premisas del viaje es lo que me lleva a la afirmación del orden de producción en términos de un campo de diaspórico. Aquí la diáspora no se pierde en el caleidoscopio de lo múltiple, tampoco alude a un mero sistema de acopio y acumulación, sino más bien, a un movimiento incesante, regulado por diversas formas de trabajo. Un espacio de diáspora es aquello que permite una permanente construcción, un signo inacabado, un conjunto de preguntas inquietantes que siempre son abiertas e inacabadas. Es un territorio de complejos enredos genealógicos de dispersión. La inclusión y su dominio intelectual no son algo escurridizo sino más bien, algo que emerge del contacto, interacción, imbricación y traducción y giro de diversas formas epistemológicas. Es el resultado de una colisión de proyectos de conocimientos críticos y post-críticos en resistencia dispersados por diversas regionalizaciones de estudio. La identidad de la inclusión es inquieta, inacabada y fluctuante. Su campo no procede por sistemas de enmarcamiento delimitando aquello que puede estar o no, dentro o fuera -trabaja en la deslimitación-. Este binomio me parece francamente reduccionista e instrumental. El campo epistemológico de la educación inclusiva es una 'extopía', es decir, es una operación basada en la exterioridad en tanto principio epistémico y exterioridad del trabajo teórico, es algo que no se descubre en el objeto, sino en la construcción del proyecto.

\section{INTERRUMPIENDO LÍMITES, CONFIGURANDO UMBRALES DE TRANSFORMACIÓN}

Al constituir la educación inclusiva una singular disposición crítica se convierte en un poderoso umbral de transformación del conocimiento y en una estrategia de intervención política significativa para los diversos sistemas-mundo. También, puede ser considerada como un mecanismo de 
audibilidad, una fuerza activadora de la consciencia, una figuración creativa en constante devenir. La singularidad de la fuerza heurístico-política del umbral que esta construye tiene, entre otras funciones, transcodificar una serie de aportes altamente significativos para la trasformación educativa. Al mismo tiempo, fomenta la emergencia de nuevos códigos que nos muestran posiciones fundamentales a través de las que su intelectualidad y formas conceptuales se transforman. Las nociones de 'umbral' y sus 'formas transformadoras de pensar', operan a través de una naturaleza (trans)relacional, es decir, trabajan interconectando en zigzag y aperturando nuevas formas de pensar e imaginar cada uno de sus sistemas-mundo.

La potencia heurística del umbral actúa en términos de un punto de fuga, abre perspectivas, crea nuevas categorías, etc. Es una operación que procede por lógica de des-fundamentación, acepta el desafío de construir nuevos marcos teóricos, en ella, lo sociopolítico es parte de conocer, es una operatoria que gira los modos habituales de pensar y producir el conocimiento. Los umbrales son clave en el trabajo epistemológico ya que permiten reencontrar la fuerza de su tarea, devienen en un punto de fuga, en formas distintivas del pensamiento. Su centro crítico aglutina la fuerza dislocante del acontecimiento, de la performatividad y de las imaginaciones desafiantes.

El conocimiento de la educación inclusiva no es exclusivamente cognitivo, sino también, es profundamente imaginativo, afectivo y volitivo. Su trabajo epistemológico coincide con los planteamientos de Chen (2010), al perseguir la construcción de una trama heurística que disloque los dispositivos de producción de la subjetividad, crea nuevas categorías que emergen por vía de dicha inyección. Sus conceptos deben ayudar a leer profundamente el presente. Estas, son, sin duda, algunas las implicancias de mayor alcance que se desprenden de la tarea de conocer a través del lente epistemológico de la educación inclusiva. Es una operación que procede por vía incorporación de novedosos alcances. Sus formas constructivas trabajan para hacer aprehensible la apertura, lo nuevo, la emergencia de un saber que trastoca formas y funciones, lo que a juicio de Zemelman (1989, p.89), "es el contenido de la realidad es una articulación entre el límite de lo dado y lo posible de darse", es signo de construcción de lo posible, es un saber que trabaja en la dialéctica apertura/ruptura de la realidad y de sus fenómenos, potenciando lo no conocido y activando las redes de transformación del mundo.

La inclusión es, en sí misma, la elaboración de un método, ¿qué implica esto? Fundamentalmente, la asunción de una tarea inventiva y de una plataforma en la interioridad del campo. Compartiendo la afirmación de Bal (2009), en su brillante obra publicada al español por Cendeac, titulada: "Conceptos viajeros en las humanidades: una guía de viaje", sostiene la necesidad de reemplazar los métodos por conceptos en campos emergentes como el aquí analizado, especialmente, cuando el analista no tiene en que 
apoyarse. Los conceptos son formas de regulación heurística y política, singulares formas de vinculación con la realidad. Para Zemelman (1992, p.45), "la productividad de plantear la cuestión metodológica en el plano categorial estriba en releer las conceptualizaciones de la realidad, a partir de la incidencia de fuerzas sociales y políticas, considerando posibles direcciones latentes en el presente". El trabajo con conceptos es siempre problemático. En tanto figuración teórica abierta trabaja a partir de múltiples niveles de análisis fomentando una ilustración de la realidad más compleja al capturar en su complejidad la totalidad de sus fenómenos.

El campo de conocimiento de la educación inclusiva puede entenderse en términos de una estructura de totalidad dispersa, nómada, no-unitaria y dinámica, en ella, no sólo convergen diversas singularidades, sino también, complejas prácticas impulsadas por sus actantes. La construcción de su conocimiento sigue la lógica "dada-dándose-por dar", lo que permite concebir su tarea heurística en términos de incompletud. La inclusión en tanto campo abierto de alteratividades es significada en términos de una fuerza heurística y política que crea realidades fuera de serie, un dispositivo de imaginación desafiante en la intervención del mundo contemporáneo. Sus formas constructivas operan en la 'estructura' y en la 'acción', es un saber atravesado por un conjunto de prácticas que cruza, transgreden y transforman lo social, lo político y lo ético, multiaxialmente.

El concepto de estructura adoptado en esta singular regionalización asume un mecanismo de adecuación a las necesidades de movimiento de la realidad social y sus problemas en permanente devenir. Para Zemelman (1992, p.93-94), constituye "un proceso de condensación de una determinada dinámica temporo-espacial”. Se convierte en un modo de concreción en zigzag, en vuelco y giro permanente, nunca en algo cerrado, sino una construcción y constelación que permite en su dinámica la inclusión de nuevos niveles y procesos de análisis y constructividad -de ahí, que el campo se ensamble por diversas convergencias epistemológicas-, albergando múltiples modos de concreción. En tal sentido, Zemelman (1992, p.67), propone "considerar la realidad como histórica, un campo abierto de acciones alternativas y de fuerzas sociales capaces de crear realidades, en cuanto direcciones posibles del movimiento de la realidad". Es signo de "reinvención de una utopía crítica, contra la resignación y el conformismo, debe superar dos problemas claves dentro de un conocimiento moderno, en sí mismo colonialista, para su realización: "el silenciamiento y la diferencia" (De Sousa, 2006, p.46).

La tarea de conocer en este campo se define desde la (re)articulación de categorías de producción problemáticas, figurativas e imaginativas. $\mathrm{Su}$ función epistemológica "asume un diálogo entre diversos esquemas teóricos, para captar la multidimensionalidad de los problemas por conocer y en 
coherencia con la forma compleja de la realidad social" (Zemelman, 1996, p.119). El estudio del movimiento en tanto condición de producción asume que la comprensión de la realidad es siempre inacabada. En efecto, tal como indica Paredes (2014, p.127).

[...] la función epistemológica supone una lógica de inclusión, coherente con una visión de apertura a lo complejo de la realidad social, mientras que la función teórica trabaja la exclusividad. Es decir, una lógica basada en un movimiento articulatorio, que va incluyendo diferentes tiempos, espacios, procesos, hacia un momento de condensación denominado "presente". Para Zemelman, "toda vez que la realidad se concibe como un movimiento articulado de procesos heterogéneos, una primera estructura de relaciones posibles ha de basarse en la lógica de la inclusión, la cual nos permite vincular conceptos sin recurrir por fuerza a una hipótesis teórica" (Zemelman 1987, 41). En otras palabras, la función epistemológica del conocimiento apela a la apertura problemática, y la función teórica, a su cierre (Zemelman 2005, 70-71).

Al inscribir la educación inclusiva su trabajo de producción intelectual en la exterioridad deviene en una peculiar forma predicativa y atributiva, una forma de pensar en términos de posibilidades.

El campo epistemológico de la educación inclusiva procede por múltiples caminos que irrumpen el orden habitual de las cosas, múltiples caminos que conducen a una serie de enfrentamientos alterativos, afectado y realineado inesperadamente por múltiples trayectorias que inscriben su fuerza heurística más allá de sus denominaciones confluyentes. Es un campo que no sólo posee la posibilidad teórica de la desterritorialización y el movimiento, más bien, se somete continuamente a este proceso.

La configuración de su dominio no procede a través de una sola síntesis, sino, mediante una acción dialéctica inquieta, asume la imposibilidad crítica de una fusión, puesto que, nos vemos obligados a pensar más allá de la teoría debido a las características del campo. Personalmente, me siento mayormente atraído a pensar 'más allá' de las formas críticas imperantes en la educación, acción devenida en una empresa destinada a extender nuestros lenguajes de comprensión, afectando sus redes de objetualización, sistemas de razonamiento y grados de inteligibilidad.

\section{CONCLUSIONES: IMAGINACIONES DESAFIANTES Y EDIFICANTES}

En la interioridad del campo de la educación inclusiva, lo especial actúa en términos de un marcador de posición para el dominio global -monocultivo mental-, mientras que, en términos heurísticos, asume una posición de palimpsesto, es decir, aquello que no puede ser borrado. Esta idea confirma la 
presencia de un movimiento bastante normativo. Sin embargo, su dominio se convierte en una red de innumerables interrelaciones que fomentan entendimientos multiaxiales acerca de su red de inteligibilidad, esta operación traza una red de análisis que ha nublado la pregunta por la autenticidad. Es necesario des-estabilizar y dislocar para poder encontrar otro tipo de aleaciones intelectuales, éticas, políticas, etc.

Otro aspecto a destacar es la no-equivalencia epistémica, metodológica y lexical entre cada una de sus partes constructivas. Si bien lo especial puede ser una forma de lo inclusivo, lo inclusivo no es necesariamente una forma de lo especial, es una operación mucho más amplia. El emparejamiento de las formas teórico-metodológicas de lo especial como parte de lo inclusivo devela una operación analítica que procede por vía de direccionalidad precaria. En parte justifica la búsqueda de formas de precarización analítica sustentadas en instrumentales formas de aproximación entre sí, develando un cruce no transformador. Esta transferencia de lo especial como rostricidad de lo inclusivo constituye un conjunto homogéneo que actúa en términos de una identidad paródica. Lo especial se convierte en el lugar fundado de la estética de lo pseudo-inclusivo. Para ello, es necesario instituir un proceso de suspensión y deslegitimación sus propias premisas de enunciación.

La travestización de lo especial como rostro de lo inclusivo actúa en términos de un 'giro hacia adentro', es decir, una especie de vuelta en un mismo idioma, ¿cómo se denominaría esta estrategia? Esta teorización ratifica una política ontológica del sujeto que queda atrapado a través del significante de la subalternidad, develando una tortuosa relación lingüística. Esta regionalización avanza por sistemas de mutación, convergencia y otras formas de análisis a través de una infinidad de proyectos de conocimiento, situados dentro de los estudios del área y los sujetos de la inclusión. Se debe promover una estrategia de de-subyugación de lo especial en lo inclusivo, pues son dos formas heurísticas distintas. Si bien, lo especial se refunda a través de la epistemología de lo inclusivo, lo especial no posee la fuerza de redefinir todos los dominios de la educación y del sistema-mundo.

La inclusión inaugura una nueva forma de pensar, asume un dispositivo de recognición de la tarea educativa y de todos los campos de las ciencias de la educación, asume una empresa transformadora de comprender y representar la realidad y su corpus de problemáticas, articula una nueva visión de mundo, un sistema interactivo complejo. La interrogante por el lugar de inscripción y residencia de la inclusión nos enfrenta a los dilemas de la pedagogía socio-espacial abriéndose a la discusión de nuevas relaciones contemporáneas, en este punto se conecta con las tareas críticas de la educación inclusiva. Inaugura una red de nuevos compromisos éticos.

La imaginación desempeña un papel fundamental en la constitución de una ontología de lo menor -revolución molecular-. La fuerza afectiva 
e imaginativa que impone el signo de la inclusión fomenta la construcción de un devenir intensivo. Inaugura un contra-espacio de creación en los diversos sistemas-mundo. Es un proceso de reinvención permanente. Su fuerza figurativa intensamente creativa posee la capacidad, difiere y altera el curso de las cosas. La inclusión no se adapta a las figuraciones del mundo establecido, cuyo deseo no persigue la preservación de las cosas, sino que tiende al cambio, a la transformación profunda. El dominio significado como educación inclusiva al concebirse como una imaginación desafiante alberga una pluralidad de deseos construye una nueva política de los afectos y del lenguaje. La inclusión no es un mero sistema de imaginación proyectiva, más bien recombina contenidos, lenguajes y formas de pensamiento, sintonizando con las complejidades del campo.

El sentido nomadista que entraña el proyecto de conocimiento en resistencia de la educación inclusiva refleja un poderoso signo político, es un "compromiso con una praxis crítica y política en términos de contramemoria, de resistencia, de responsabilidad, de saberes situados y de una política de localización" (Braidotti, 2004, p.66). Es el espacio heterotópico del que hablo en mis textos es justamente un contra-espacio, que

[...] necesita construir y preservar espacios utópicos y ucrónicos que sirven para definir y consolidar todos los demás espacios en que viven y se socializan los individuos. Lugares, dice, que se oponen a todos los demás, que tienen como destinación el borramiento de todos los demás, su neutralización o purificación. Son como contraespacios, utopías localizadas que conocen perfectamente los niños (por ejemplo la cama de los padres cuando se ausentan o el sótano). Son transgresivos y albergan un espacio de libre expresión donde todo lo que está en contra del orden establecido, de las normas, todo lo que no sigue las leyes, encuentra una posibilidad de existencia (González, 2018, p.181). 


\section{BIBLIOGRAFÍA}

Ávila, I. (2014). El nomadismo filosófico de Rosi Braidotti: una alternativa materialista a la metafísica de la presencia. Tabula Rasa, 21, 167-184.

Bal, M. (2009). Conceptos viajeros en las humanidades. Una guía de viaje. Murcia: Cendeac.

Braidotti, R. (2000). Sujetos nómades. Buenos Aires: Paidós.

Braidotti, R. (2002). Metamorfosis. Hacia una teoría materialista del devenir. Madrid: Akal.

Braidotti, R. (2004). Feminismo, diferencia sexual y subjetividad nómade. Barcelona: Gedisa.

Braidotti, R. (2009). Transposiciones. Barcelona: Gedisa.

Buck- Morss, S. (1997). Origen de la dialéctica negativa. México: Siglo XXI.

Burman, E. (2017). Child as method: implications for decolonising educational research. International Studies in the Sociology of Education, 28(3), 1-23. https://www.tandfonline.com/doi/abs/10.1080/09620214.2017.1412266

Cabrera, M. \& Vargas Monroy, L. (2014). Transfeminismo, decolonialidad y el asunto del conocimiento: Algunas inflexiones de los feminismos disidentes contemporáneos. Universitas Humanística, 78, 19-37.

Cardenal, T. (2012). La extraña dentro: el feminismo nómada de Rosi Braidotti. https://zaguan.unizar.es/record/9242/files/TAZ-TFG-2012-695.pdf

Castillo, K. (2019). Claves teóricas en Manuel de Landa. Andamio, 40(17), 229-250.

Chen, K. (2010). Asia as method: towards deimperialization. Durham: Duke University Press.

Cho, S., Crenshaw, K. \& McCall, L. (2013). Toward a field of intersectionality studies: theory, applications, and praxis. Signs 38, 785-810.

Deleuze, G. \& Guattari, F. (1968). Mil mesetas. México: FCE.

Deleuze, G. (2005). La isla desierta y otros textos. Madrid: Pretextos.

De Landa, M. (2016). Assemblage Theory. Edimburgo: Edinburgh University Press.

De Sousa, B. (2006). Una epistemología del sur: la reinvención del conocimiento y la emancipación social. México: Siglo XXI/CLAcso.

Escobar, A. \& Osterwell, M. (2009). Movimientos sociales y la política de lo virtual. Estrategias deleuzianas", en: Castillo, K. (2019). Claves teóricas en Manuel de Landa. Andamio, 40(17), 229-250.

González, B. (2018). La ética diferencial de Rosi Braidotti. Agora. Papeles de filosofía, 37(2), 173-191.

Grossberg, L. (1996). "On postmodernism and articulation: an interview with Stuart Hall”, en: Critical Dialogues in Cultural Studies, ed. D Morley, K-H Chen. (131-50). New York: Routledge.

Hill Collins, P. (2015). Intersectionality. As critical social theory. Duke University Press. 
Hill Collins, P. (2015). Intersectionality's Definitional Dilemmas. https:// edspace.american.edu/culturallysustainingclassrooms/wp-content/ uploads/sites/1030/2017/09/annurev-soc-073014-112142.pdf

Ocampo, A. (2018). Las políticas de la mirada y la comprensión epistemológica de la Educación Inclusiva: ¿en qué sentido la Educación Inclusiva es para todo el mundo?, Polyphōnía. Revista de Educación Inclusiva, Santiago, 1(2) 15-51

Ocampo, A. (2019). Contornos teóricos de la educación inclusiva. Revista Boletín Redipe, 8 (3), 66-95.

Palaisi, M.A. (2018). Saberes nómades. El sujeto nómade como contra-espacio epistemológico. Enrahonar. An International Journal of Theoretical and Practical Reason, 60, 57-73.

Paredes, J. P. (2014). Pensamiento epistémico y conocimiento social: emergencias y potencialidades en la investigación social. Revista de Estudios Sociales, 48, 125-138.

Rajchman, J. (2004). Constructions. New York: The мIт Pres.

Said, E.W. (2000). “Traveling Theory.” The Edward Said Reader. New York: Vintage Books.

Young, I.M. (2002). Justicia y Política de la Diferencia. Valencia: Cátedra.

Zemelman, H. (1989). Uso crítico de la teoría. En torno a las funciones analíticas de la totalidad. México: El Colegio de México.

Zemelman, H. (1992). Los horizontes de la razón. I. Dialéctica y apropiación del presente. México: Antrophos.

Zemelman, H. (1996). Problemas antropológicos y utópicos del conocimiento. México: Colegio de México. 